\title{
1 Evolution of thermal physiology alters projected species distributions under
}

\section{2 climate change}

4 Sara J.S. Wuitchik ${ }^{1, \dagger, *}$, Stephanie Mogensen ${ }^{1}$, Tegan N. Barry ${ }^{1}$, Antoine Paccard ${ }^{2, \ddagger}$,

5 Heather A. Jamniczky ${ }^{3}$, Rowan D.H. Barrett ${ }^{2,}$, and Sean M. Rogers ${ }^{1,4, \S}$

$7{ }^{1}$ Department of Biological Sciences, University of Calgary, 2500 University Dr NW, Calgary,

$9 \quad{ }^{2}$ Redpath Museum and Department of Biology, McGill University, 845 Sherbrooke St W,

10 Montreal, QC, H3A 0G4, CANADA

11 3 Department of Cell Biology \& Anatomy, Cumming School of Medicine, University of Calgary,

123330 Hospital Dr NW, Calgary, T2N 4N1, CANADA

$13{ }^{4}$ Bamfield Marine Sciences Centre, 100 Pachena Rd, Bamfield, BC, V0R 1B0, CANADA

14 §equal co-senior authors

15

16 Running title: Evolution alters projected species ranges

17

18 *Corresponding author: Sara J.S. Wuitchik

19 E: sjswuit@g.harvard.edu

20 T: 857-292-9977

$\uparrow$ Present affiliations: Informatics Group, Harvard University, 38 Oxford St, Cambridge, MA, 02138, USA \& Department of Biology, Boston University, 5 Cummington Mall, Boston, MA, 02215 , USA $\ddagger$ Present affiliation: McGill University Genome Center, 740 Dr Penfield Avenue, Montreal, QC, H3A 1A5, Canada 


\section{Abstract}

Species distribution models (SDMs) are widely used to predict range shifts but could be

23 unreliable under climate change scenarios because they do not account for evolution. The

24 thermal physiology of a species is a key determinant of range and thus incorporating thermal trait

25 evolution into SDMs might be expected to alter projected ranges. We identified a genetic basis

26 for physiological traits that evolve in response to temperature change in threespine stickleback

27 (Gasterosteus aculeatus). Using these data, we created geographic range projections under two

28 climate change scenarios where trait data was either static ('no evolution' model), allowed to

29 evolve at observed evolutionary rates for the trait ('evolution' model), or allowed to evolve at a

30 rate of evolution scaled in association with the variance that is explained by quantitative trait loci

31 (QTL; 'scaled evolution' models). We show that incorporating these traits and their evolution

32 substantially altered the projected ranges for a widespread panmictic marine population, with

33 over 7-fold increases in area under climate change projections. Evolution-informed SDMs should

34 improve the precision of forecasting range dynamics under climate change, and aid in their

35 application to management and the protection of biodiversity.

37 Keywords: thermal biology, critical thermal limits, evolution, species distribution models,

38 climate change, threespine stickleback 


\section{Introduction}

45 Temperature is a powerful driver of global biogeography and species distributions

46 frequently reflect temperature gradients in both aquatic and terrestrial habitats (Hochachka \&

47 Somero, 2002). Many species adopt thermal strategies (such as thermoregulation or acclimation)

48 that determine their thermal niche (Coutant, 1987; Huey \& Kingsolver, 1989; Huey \& Slatkin,

49 1976) and thermal traits can provide a target for directional selection if the environment changes

50 to include temperatures outside the range encompassed by the thermal niche. Adaptation can thus

51 permit species to persist at temperatures that would have previously led to extirpation (Hoffman

52 \& Sgrò, 2011; Sexton, McIntyre, Angert, \& Rice, 2009). Under moderate climate change

53 scenarios, mean global oceanic temperature is projected to increase in excess of $2^{\circ} \mathrm{C}$ by the end

54 of the century (IPCC, 2014), with more extreme changes predicted in localized regions (Eyer,

55 Blumenfeld, \& Vargo, 2019; Walther et al., 2002) for both cooling and warming events (Hu,

56 Guan, Tian, \& Ren, 2018). Accurately predicting species distribution patterns under climate

57 change therefore requires data for temperature-associated adaptive trait evolution.

58 While the climate and ocean temperatures are warming overall, thermal events

59 characterized by both cold and heat extremes are occurring with increasing frequency (Hu et al.,

60 2018; IPCC, 2014, 2018; Stott, 2016). Regionally downscaled environmental changes can be

61 highly spatially heterogenous relative to global temperature trends, and are likely to be the most

62 relevant for species-specific responses in the context of contemporary climate change (Walther et

63 al., 2002). For example, range expansions of marine species have been mediated by both ocean-

64 scale warming and also regional cooling that allowed for species invasion (Zeidberg \& Robison,

65 2007). In such cases, population persistence will rely on both upper and lower critical thermal

66 limits, with thermal events forcing organisms to respond independently to extreme heat and 
67 extreme cold in separate events (Herring, Christidis, Hoell, Hoerling, \& Stott, 2020; Herring et

68 al., 2018; Herring, Hoerling, Kossing, Peterson, \& Stott, 2015; Hu et al., 2018; Walther et al.,

69 2002). Importantly, adaptation in one thermal trait can also shift the thresholds of correlated

70 thermal traits (Buckley \& Huey, 2016; Denny \& Dowd, 2012; Hoffman \& Sgrò, 2011; Huey \&

71 Kingsolver, 2011). Associations between traits influence the rate of trait adaptation and thus

72 correlated traits must be considered when attempting to predict future species distributions under

73 climate change (Hoffman \& Sgrò, 2011). While there have been recent steps to incorporate

74 theoretical trait evolution into SDMs (Bush et al., 2016; Kearney \& Porter, 2009), to date, no

75 model has used empirical estimates of evolutionary rates to inform projected species

76 distributions under climate change scenarios.

77 Due to widespread phenotypic variation (Hendry, Peichel, Matthews, Boughman, \&

78 Nosil, 2013), genomic resources (Jones, Grabherr, et al., 2012), the availability of temperature-

79 associated evolutionary trait data (Barrett et al., 2011; Morris, Bowles, Allen, Jamniczky, \&

80 Rogers, 2018), and the ability to artificially breed multiple hybrid generations in a common

81 garden lab environment, threespine stickleback (Gasterosteus aculeatus Linnaeus 1758, Fig. 1a)

82 are a useful vertebrate species for understanding the impact of adaptation on range dynamics

83 under climate change. In particular, the availability of a regionally downscaled climate model for

84 the Pacific Northwest (Alexander et al., 2018; IPCC, 2014; Reynolds et al., 2007) make

85 panmictic marine populations of G. aculeatus in the eastern Pacific Ocean (Kirch, Romundset,

86 Gilbert, Jones, \& Foote, 2021; Morris et al., 2018) an ideal system for testing how adaptive trait

87 variation could affect projections of species range distributions under climate change (Barrett \&

88 Hendry, 2012). 
The objective of this study is to incorporate ecologically and evolutionarily relevant data

90 on thermal traits into end-of-century projections of species distribution models. To accomplish

91 this, we assessed physiological and behavioural temperature-associated traits in two marine and

92 two freshwater populations of threespine stickleback, as well as within-population F1 families

93 and marine-freshwater hybrid F1 and F2 families. We used the hybrid families to construct

94 genetic linkage maps and identified multiple quantitative trait loci associated with thermal

95 preference as well as upper and lower critical thermal limits. Using these genetically-based traits

96 and empirically derived evolutionary rate data for lower critical limits in this species (Barrett et

97 al., 2011), we constructed species distribution models that integrated the trait data reported in

98 this study and allowed those traits to evolve under two climate change scenarios and three

99 distinct types of evolutionary models.

\section{Materials and Methods}

$101 \quad$ Sample collection and husbandry

102 We collected adult Gasterosteus aculeatus (Fig. 1a) from two marine populations

103 (Bamfield, M1, 4849'12.69"N 125 8'57.90"W; Garden Bay Lagoon, M2, 49³7'52.84"N 124

104 1'49.26"W) and two freshwater populations (Hotel Lake, FW1, 49³8'26.94"N 124 3'0.69"W;

105 Klein Lake, FW2, 4943'32.47"N 12358'7.83"W) in southwestern British Columbia (Fig. 1b).

106 Individuals were maintained in a flow-through system and photoperiod that mimicked the source

107 populations during collection periods before transport. We transported the fish to the Life and

108 Environmental Sciences Animal Resources Centre at the University of Calgary, where we

109 separated the fish into population-specific $113 \mathrm{~L}$ glass aquaria at a density of approximately 20

110 fish per aquarium. We acclimated marine individuals to freshwater salinity over one week and

111 maintained fish in a common environment (salinity of 4-6 ppt, water temperature of $15 \pm 2{ }^{\circ} \mathrm{C}$, 
112 and a photoperiod of 16L:8D). Individuals were allowed to acclimate for at least 2 weeks before

113 experiments ( 1 week for stress reduction post-transfer, 1 week for common garden environment

114 acclimation and salinity ramp). Each common garden aquarium was on a closed system with

115 individual filters, air stones, and water supply. We fed all adult fish ad libitum once per day with

116 thawed bloodworms (Hikari Bio-Pure Frozen Bloodworms). All collections and transfers were

117 approved by the Department of Fisheries and Oceans (marine collections and transfers), the

118 Ministry of Forests, Lands, and Natural Resource Operations (freshwater collections), and the

119 Huu-ay-aht First Nations (marine collections).

120 Crossing design for marine and freshwater F1 families

121 We collected eggs from females and fertilized the eggs with extracted testes from

122 euthanized males. We transferred the fertilized egg mass to a mesh-bottomed egg incubator

123 suspended in a $37 \mathrm{~L}$ aquarium for hatching. Each hatching aquarium was maintained with a

124 single air stone and a filter. Once hatched, we reared the larval fish in $37 \mathrm{~L}$ hatching aquaria until

125 they reached a total length (TL) of approximately $1 \mathrm{~cm}$, after which we split the families into

126 family-specific $113 \mathrm{~L}$ aquaria to maintain suitable densities. We fed the larval fish ad libitum

127 twice daily with live Artemia spp. nauplii, and then gradually transitioned the diet to chopped,

128 thawed bloodworms (Hikari Bio-Pure Frozen Bloodworms) ad libitum once daily as they

129 reached approximately $2 \mathrm{~cm}$ TL. The F1 families were maintained in a common garden

130 environment identical to that of the F0 populations. We produced one F1 family for each

131 population (M1_F1, M2_F1, FW1_F1, and FW2_F1).

132 Crossing design for hybrid mapping families

133 To generate genetically heterogeneous marine-freshwater F1 families from wild F0

134 parents, we collected eggs from marine females and fertilized the eggs with extracted testes from 
135 euthanized freshwater males. Egg masses were hatched, and juveniles were reared, as detailed

136 above. Overall, we produced one F1 family of M1xFW1 hybrids (hereafter referred to as H1_F1)

137 and three F1 families of M1xFW2 hybrids (hereafter referred to as H2_F1). The hybrid F1

138 families were maintained in a common garden environment identical to that of the F0

139 populations. To generate F2 families for linkage map construction, we crossed individuals from

140 the same F1 family with the same methodology used to generate the F1 families. Overall, we

141 produced one F2 family of $\mathrm{H} 1 \mathrm{xH} 1$ hybrids (referred to as H1_F2) and three families of H2xH2

142 hybrids (referred to as H2_F2_1, H2_F2_2, and H2_F2_3). All F2 individuals were raised as

143 described above in a common garden environment identical to that of the F0 and F1 individuals

144 to ensure consistent history.

145 Thermal tolerance and preference experiments

146 To assess the lower and upper limits of physiological thermal tolerance, we conducted

147 standard critical thermal minimum (CTmin) and maximum (CTmax) experiments on adult fish

148 (Barrett et al., 2011; Fangue, Hofmeister, \& Schulte, 2006; Hutchison, 1961). At these sublethal

149 limits, the fish experiences a loss of equilibrium (LOE) at which they lose the ability to escape

150 conditions that would ultimately lead to their death in nature (Beitinger, Bennett, \& McCauley,

151 2000). Our experimental tank held $1000 \mathrm{~mL}$ glass beakers aerated individually to prevent

152 thermal stratification. Before each experiment, individuals were fasted for 24 hours. After a 15-

153 minute acclimation to the experimental apparatus in the individual beakers, we cooled or heated

154 the water (for CTmin or CTmax, respectively) at a rate of approximately $0.33{ }^{\circ} \mathrm{C} \mathrm{min}^{-1}$. We

155 assessed wild F0 individuals $\left(n_{M 1}=32, n_{M 2}=14\right.$, Fig. $1 \mathrm{c} ; n_{F W 1}=15, n_{F W 2}=16, N=77$; Fig. S1)

156 and lab raised F1 $\left(n_{M 1_{-} F 1}=13, n_{M 2_{-} F 1}=15, n_{F W 1_{-} F 1}=15, n_{F W 2_{-} F 1}=15, N=58 ;\right.$ Fig. S2 $)$ and F2

157 individuals $\left(n_{H 1 \_F 2}=28, n_{H 2 \_F 2 \_l}=36, n_{H 2 \_F 2 \_2}=21, n_{H 2 \_F 2 \_3}=17, N=102 ;\right.$ Fig. S3 $)$. All 
158 individuals were assessed for CTmin, allowed to recover for at least three days, then assessed for

159 CTmax to keep thermal stress history consistent. The onset of erratic behaviours associated with

160 a behavioural stress response occurred below $5.0^{\circ} \mathrm{C}$ and above $25.0^{\circ} \mathrm{C}$ during $\mathrm{CTmin}$ and

161 CTmax experiments, respectively. Normal behaviour was observed between $5.0{ }^{\circ} \mathrm{C}$ and $25.0{ }^{\circ} \mathrm{C}$,

162 whereas outside of those temperatures, individuals gradually exhibited more extreme stress

163 responses (e.g., increased gilling rate, erratic movement, muscle spasms, listing, as outlined by

164 the Canadian Council of Animal Care guidelines) until reaching LOE and the inability of an

165 individual to right itself (the experimental endpoint) (Barrett et al., 2011; Fangue et al., 2006;

166 Hutchison, 1961).

To assess the range of behavioural thermoregulation, we conducted thermal preference

168 experiments in a temperature Shuttlebox (Loligo Systems, Viborg, Denmark). Experimental

169 pools were set with a static gradient of $10{ }^{\circ} \mathrm{C}$ in the cool side and $20^{\circ} \mathrm{C}$ in the warm side,

170 connected with a water bridge at $15^{\circ} \mathrm{C}$ (acclimation temperature). Temperature was continually

171 monitored and recorded by immersed temperature probes, connected to a computer-driven

172 temperature controller and data acquisition system (DAQ-M, Loligo Systems, Viborg,

173 Denmark). Movement in the Shuttlebox was tracked by an infrared-sensitive uEye USB 2.0

174 camera (IDS Imaging Development Systems GmbH, Obersulm, Germany) which connected to

175 Shuttlesoft (v2, Loligo Systems, Viborg, Denmark) and allowed monitoring of fish movement.

176 Following recovery from CTmax experiments (at least three days), individuals were acclimated

177 in the Shuttlebox for 15 minutes, with entry at 'cool' or 'warm' pool randomized, to allow for

178 exploration of the gradient. After acclimation to the experimental apparatus, the movement of

179 each individual was tracked in 1 second intervals for 30 minutes, recording the preferred ambient

180 water temperature (thermal preference). Individuals were assessed individually in the Shuttlebox 
181 apparatus to avoid any confounding social behaviours (e.g., as seen in shoaling behaviours,

182 Cooper, Adriaenssens, \& Killen, 2018). At the time of data collection for thermal trait

183 experiments, all individuals were adults.

184 Relationships between all thermal traits separated by population and generation were 185 assessed using the Pearson product-moment correlation with the corrplot (v0.84, Wei et al., 186 2017) and Hmisc (v3.14-0, Harrell, 2014) packages in R (R Core Team, 2019).

187 Isolation and characterization of single nucleotide polymorphisms (SNPs)

Genomic DNA was extracted from caudal fin tissue using a phenol-chloroform-based

189 protocol. We digested tissues overnight in digestion buffer and proteinase $\mathrm{K}$ at $55^{\circ} \mathrm{C}$, then

190 performed multiple phenol-chloroform and ethanol washes to isolate the DNA. We assessed the

191 quantity of the extracted DNA using the Quant-iT PicoGreen dsDNA assay kit (ThermoFisher

192 Scientific, Waltham, MA, USA) and Synergy HT plate reader with the Gen5 associated software

193 (BioTek, Winooski, VT, USA). We prepared restriction site-associated DNA (RAD) libraries

194 (Peterson, Weber, Kay, Fisher, \& Hoekstra, 2012) using MluCl and NlaIII restriction (New

195 England Biolabs, Ipswich, MA, USA), ligation of individual barcodes, and pooling of 48

196 individuals per library at equimolar concentrations. We performed a final PCR to amplify DNA

197 and add library-specific indices to allow for pooling of multiple libraries. We sequenced three

198 libraries at McGill University and Génome Québec Innovation Center on one lane of Illumina

199 HiSeq 4000 (Illumina Inc., San Diego, CA, USA).

200 Assembly of the genetic linkage maps

201 After barcode demultiplexing and filtering out low quality reads in STACKS (Catchen,

202 Hohenlohe, Bassham, Amores, \& Cresko, 2013), we removed PCR duplicates from the raw

203 sequences and aligned to the G. aculeatus reference genome (Jones, Grabherr, et al., 2012) using 
204 the Burrows-Wheeler transform (Li \& Durbin, 2010). Individual libraries were concatenated and

205 filtered (Puritz, Hollenbeck, \& Gold, 2014) using vcftools v3.0 (Danecek et al., 2011) and then

206 split into chromosome-specific VCF files to assemble the linkage maps chromosome by

207 chromosome. We assigned markers to a linkage group with an initial LOD score of 3 after

208 filtering out markers that showed high levels of segregation distortion and missing observations

209 (> 20\% missing data) in Lep-MAP3 (Rastas, 2017). Unassigned markers were subsequently

210 added to the existing linkage group at a LOD score of 3 and a size limit of 5 markers per linkage

211 group. We ordered the markers using a minimum posterior value of 0.001 and collapsed multiple

212 markers when the probability difference between markers was < 0.01 (Rastas, 2017). The final

213 linkage map was phased in Lep-MAP3 (Rastas, 2017) and subset for use in R (R Core Team,

214 2019) with a custom Python script to generate a list of informative SNPs to use in subsequent

215 analyses with the qtl v1.44-9 (Broman, Wu, Sen, \& Churchill, 2003) package. The final linkage

216 maps were similar across populations in number of markers, length, and spacing between

217 markers, though the H2_F2 map had a higher density of markers (Table S1).

\section{Quantitative trait loci (QTL) mapping}

219 We analysed families separately with the same methodology to assess the presence of

220 QTL associated with the thermal traits. We calculated conditional genotype probabilities using a

221 hidden Markov model, allowing for possible genotyping errors at a level of 0.0001 using a

222 Kosambi mapping function with a fixed step width, prior to running genome scans with a single

223 QTL model (Arends, Prins, Broman, \& Jansen, 2014; Broman \& Sen, 2009). We determined the

224 logarithm of the odds (LOD) score significance thresholds for each trait through permutation

225 tests for each family (5,000 permutations per chromosome, Table 1). We pulled significant QTL

226 above the genome-wide significance threshold ( $\alpha=0.05$, Greenwood et al., 2011), calculated 
227 confidence intervals of QTL location based on nearby markers, and estimated the percent

228 variance explained by each QTL peak marker. We identified two QTL associated with CTmin,

229 two QTL associated with CTmax, three QTL associated with thermal preference, and four QTL

230 associated with core body temperature during behavioural thermoregulation (Table 1, Fig. 2).

\section{Environmental variables and species distribution models (SDMs)}

We compiled environmental data widely used in the construction of SDMs to estimate

233 suitable habitat in both present day and end-of-century forecasts (Wiens, Stralberg, Jongsomjit,

234 Howell, \& Snyder, 2009), including bathymetry, sea ice extent and concentration, salinity, and

235 sea surface temperature. We used 2014 data as our baseline year to match the forecasting

236 baseline of the Fifth Assessment Report (IPCC, 2014). We assumed a suitable habitat range for

237 this species in the Pacific Northwest to consist of coastal areas (water depth less than $200 \mathrm{~m}$ )

238 where sea ice is never present (i.e., no sea ice at the maximum extent). G. aculeatus has a broad

239 salinity tolerance (Bayly, 2003; Divino et al., 2016) and salinity is not limiting in any part of the

240 range (Zweng et al., 2013), therefore salinity was not included in the final present day or

241 forecasted models. We obtained bathymetry data from the General Bathymetric Chart of the

242 Oceans (GEBCO) of the British Oceanographic Data Centre (Weatherall et al., 2015), and

243 maximum sea ice extent data from the Multisensory Analyzed Sea Ice Extent - Northern

244 Hemisphere (MASIE-NH) product (Fetterer, Savoie, Helfrich, \& Clemene-Colon, 2010). We

245 obtained maximum and minimum daily mean sea surface temperature (SST) from Reynolds et al.

246 (2007). Sea surface temperature was used as a proxy for water temperature. Stickleback thermal

247 trait data were used to set the limits of the distribution within the possible area delineated by sea

248 ice free water of a suitable depth (Table S2). Thermal trait measurements were based on our

249 experimental findings reported in the present study. 
In the end-of-century forecast for suitable habitat, we assumed bathymetry to be

251 consistent with the modern scenario. In contrast, because the Arctic Ocean is projected to be

252 predominantly free of sea ice in the summer by the end of the century (Johannessen et al., 2004),

253 with significant end-of-century reductions in winter/spring sea ice concentration (reduced to a

254 concentration of 0.1 at the Seward Peninsula, Johannessen et al., 2004), we conservatively set the

255 maximum northern extent of the suitable habitat to the western tip of the Seward Peninsula

$256\left(65^{\circ} 35^{\prime} \mathrm{N}\right)$. The extent of sea ice was kept consistent between scenarios to control for area in

257 calculations of range expansion. The water temperatures were increased based on projections for

258 large marine ecosystems of Northern Oceans from global climate models (Alexander et al., 2018;

259 IPCC, 2014). Maps were created in R (R Core Team, 2019) using the packages raster v. 3.3-13

260 (Hijmans et al., 2020) and rgeos v. 0.5-3 (Roger, Stuetz, Ove, Giraudoux, \& Santilli, 2020).

261 We incorporated experimental data on the wild marine populations (Fig. 1c) to

262 understand how inclusion of trait data may affect range projections under climate change. These

263 trait-defined envelopes were overlain on the suitable habitat background to delineate projected

264 presence based on thermal traits in both current day and IPCC-projected RCPs 4.5 and 8.5. The

265 trait values were kept constant (i.e., not changed) in the 'no evolution' projections. In contrast, in

266 the 'evolution' projections, we allowed CTmin to evolve $2.5^{\circ} \mathrm{C}$ lower (i.e., $2.5^{\circ} \mathrm{C}$ below the

267 CTmin boundary in the 'no evolution' projection) by the end of the century, based on a rate of

2680.63 haldanes estimated from a selection experiment previously conducted on populations

269 belonging to the same admixed genetic cluster as the sampled populations (Barrett et al., 2011;

270 Morris et al., 2018). Since the rate of CTmin evolution used here is an estimate based on whole-

271 organism tolerance (Barrett et al., 2011), and thermal trait evolution is constrained by the

272 underlying genetic architecture of the trait, we next explored how selection acting on discrete, 
273 identifiable loci would impact evolutionary rates, and the subsequent effects on projected habitat

274 range. To do so, we constructed models that scaled the evolutionary rate of CTmin based on the

275 observed genetic architecture from our QTL mapping ('scaled evolution’ projections). However,

276 an important restriction in the evolution of CTmin for all models incorporating trait evolution

277 ('evolution' and 'scaled evolution' projections) was a hard boundary at $0{ }^{\circ} \mathrm{C}$, with the

278 assumption that population persistence in a sub-zero environment would require additional

279 adaptations to CTmin improvement (e.g., extreme adaptations observed in Antarctic notothenioid

280 fishes, Cheng \& Detrich, 2007; Detrich, Parker, Williams, Nogales, \& Downing, 2000; Shin et

281 al., 2014).

To quantify the differences in estimated suitable habitat under current day and end-of-

283 century conditions, we compared areas for each warming scenario to the equivalent scenario

284 under current conditions. Similarly, to compare the differences in evolutionary scenarios, the

285 area of each end-of-century evolutionary trajectory was compared to either the contrasting RCP

286 projection or scaled evolution projection. For these comparisons, we used North Pole Lambert

287 azimuthal equal area projection for all maps, and georeferenced to known landmarks in ArcGIS

288 v10.8 (Environmental Systems Research Institute, 2017) to calculate area from the maps

289 generated in $\mathrm{R}$ (R Core Team, 2019)(conversion ratio of 7873.42).

290 Results

291

292 Genetic basis of thermal traits

293 Stickleback exhibited a wide thermal tolerance range bounded by a mean CTmin of 1.89

$294{ }^{\circ} \mathrm{C}\left(+/-1.04{ }^{\circ} \mathrm{C} \mathrm{SD}\right)$ and a mean CTmax of $30.1{ }^{\circ} \mathrm{C}\left(+/-1.78{ }^{\circ} \mathrm{C}\right.$ SD)(Fig. 1c), with these

295 physiological traits being highly correlated $(r=0.79)$. These populations also tolerated a wide

296 range of temperatures within which there was no observable stress response $\left(5.0-25.0^{\circ} \mathrm{C}\right)$. 
297 Thermal preference values were slightly above the acclimation temperature, but with more

298 variance around the mean than is observed in the physiological traits $\left(16.7+/-3.19^{\circ} \mathrm{C}\right)$.

299 To determine if these measured thermal traits have a genetic basis and could therefore

300 evolve in response to natural selection, we raised hybrid marine-freshwater $\mathrm{F} 1(\mathrm{~N}=2)$ and F2

$301(\mathrm{~N}=4)$ families under common garden conditions and used these fish for genome-wide linkage

302 map construction (Table S1) and quantitative trait loci (QTL) mapping. Using 41,840 high-

303 quality single nucleotide variants generated from restriction site-associated DNA (RAD)

304 sequencing, we identified two significant QTL for CTmin, two significant QTL for CTmax, and

305 three significant QTL for thermal preference (Table 1). The trait variance that each QTL

306 explained ranged from 28.9\% (CTmin QTL on linkage group III) to $87.1 \%$ (thermal preference

307 QTL on linkage group VII).

308 SDM for current day

309 We used these genetically based traits to first inform the boundaries of three distinct

310 environmental regions in species distribution models (SDMs): i) a 'normal behaviour' envelope

311 that included environmental temperatures associated with an absence of an observable

312 behavioural stress response $\left(5.0\right.$ to $\left.25.0^{\circ} \mathrm{C}\right)$, ii) a 'within physiological limits' envelope that

313 included environmental temperatures within the range of their measured physiological limits (1.8

314 to $30.1^{\circ} \mathrm{C}$ ), and iii) an 'outside physiological limits' envelope with environmental temperatures

315 that fall outside the measured physiological limits (below 1.8 and above $30.1^{\circ} \mathrm{C}$ ). Based on sea

316 ice extent and bathymetry alone, our present-day suitable habitat model suggests a marine range

317 distribution for this population from the southern Bering Sea to northern Washington state, and

318 along the southeast Alaskan Panhandle (combined shaded area in Fig. 3a). When we include

319 thermal trait data from the wild marine populations, nearly the entire range of suitable habitat 
320 was unaffected by thermal tolerance limits, with the exception of a slight restriction at the

321 northern end of the range (Fig. 3a). However, when restricted to the Normal Behaviour area, the

322 range becomes confined to the west of the northern tip of Kodiak Island (Fig. 3a), a limit

323 coinciding with the northern-most known marine population in the Pacific Northwest genetic

324 cluster (Morris et al., 2018).

325 SDMs without trait evolution

326 End-of-century IPCC projections resulted in a substantial increase in the overall suitable

327 habitat area for stickleback, with a 2.25 -fold or $1,338,219 \mathrm{~km}^{2}$ increase (combined shaded area in

328 Fig. 3b-e) in association with a reduction in sea ice concentration at the northern end of the

329 range. When temperature increases as projected by RCP 4.5, the 'no evolution' model projects a

$330 \quad 5.86$-fold $\left(1,011,949 \mathrm{~km}^{2}\right)$ increase in the Normal Behaviour area within this newly suitable

331 habitat (Fig. 3b) when compared to the current day model. Under RCP 8.5, the entirety of

332 suitable habitat area remains within tolerable limits in the 'no evolution' model (Fig. 3c), with a

333 smaller proportion of the range (10.7\%) falling outside of the Normal Behaviour area as

334 compared to RCP 4.5 conditions.

335 SDMs incorporating trait evolution

336 Incorporating the evolution of CTmin into the SDMs ('evolution' model) results in a

337 large increase in the proportion of suitable habitat that falls within the Normal Behaviour area.

338 We allowed CTmin to evolve by 0.63 haldanes, which is equal to the rate observed for CTmin in

339 marine stickleback (Barrett et al., 2011). At this rate, the population reaches the hard limit of $0^{\circ} \mathrm{C}$

$340 \quad\left(1.8^{\circ} \mathrm{C}\right.$ lower than the current population CTmin) after 2-3 generations (2-3 years) - well before

341 the end of the century. Under RCP 4.5, almost all (99.9\%) of the suitable habitat range falls

342 within the Normal Behaviour area (Fig. 3d), while under the RCP 8.5 'evolution' model, the 
343 entire range of suitable habitat is within the Normal Behaviour area (Fig. 3e). These represent a

3447.45 -fold increase $\left(1,336,123 \mathrm{~km}^{2}\right)$ for RCP 4.5 and 7.46 -fold increase $\left(1,338,219 \mathrm{~km}^{2}\right)$ for RCP

3458.5 in the Normal Behaviour area when compared to the current day model.

346 We next scaled CTmin to evolve at a rate equivalent to the response expected if selection

347 acted solely on the detected CTmin QTL on either linkage group III (PVE = 28.9\%) or XXI

$348(\mathrm{PVE}=53.7 \%)$. Under RCP 4.5 when CTmin evolved at a rate of $28.9 \%$ or $53.7 \%$ of $2.5{ }^{\circ} \mathrm{C}$,

349 there was a decrease in the area of the Normal Behaviour envelope of $201,230 \mathrm{~km}^{2}$ or 123,958

$350 \mathrm{~km}^{2}$ (Fig. S4) in the 'scaled evolution' model when compared to the 'evolution' model. However,

351 these decreases in the area of the Normal Behaviour envelope in comparison to the 'evolution'

352 model still represent a substantial increase of $122,943 \mathrm{~km}^{2}$ and $200,216 \mathrm{~km}^{2}$ when compared to

353 the 'no evolution' model. Allowing CTmin to evolve at these scaled rates under RCP 8.5 resulted

354 in a decrease of $31,682 \mathrm{~km}^{2}$ and $4,035 \mathrm{~km}^{2}$, respectively, in the area of the Normal Behaviour

355 envelope (Fig. S5) when compared to the 'evolution' model, which translate to an increase of

$356131,092 \mathrm{~km}^{2}$ and $158,739 \mathrm{~km}^{2}$ in comparison to the 'no evolution' model. Relative to the current

357 day model, there was an average increase of $1,173,529(+/-54,640 \mathrm{SD}) \mathrm{km}^{2}$ in the area of the

358 Normal Behaviour envelope under RCP 4.5 and an average increase of 1,320,361 (+/- 19,549

$359 \mathrm{SD}) \mathrm{km}^{2}$ under RCP 8.5.

360 Discussion

361 In this study, we have produced the first 'evolution-informed' species distribution models

362 that incorporate empirical data for temperature-associated traits and their evolution to understand

363 how end-of-century projections change with the inclusion of this data. We assessed physiological

364 (critical thermal minimum, CTmin, and maximum, CTmax), and behavioural (thermal

365 preference) thermal traits for threespine stickleback from wild marine and freshwater 
366 populations, as well as hybrid F1 and F2 families. We provide novel characterization of

367 quantitative trait loci underlying these traits in this species, which are likely to be important

368 genetic targets of selection under climate change. Finally, we incorporated this trait data and an

369 empirical estimate of evolutionary rate for one of these traits into mechanistic species

370 distribution models under two climate change scenarios (RCP 4.5 and RCP 8.5). When trait data

371 is included in projections but held constant over warming scenarios (i.e., 'no evolution' models),

372 there is a 6-fold (RCP 4.5) and 7-fold (RCP8.5) increase in the Normal Behaviour models. The

373 geographic ranges projected for the end-of-century species distributions increased by over 7-fold

374 when CTmin was allowed to evolve in the 'evolution' models. Additionally, when CTmin was

375 allowed to evolve at a rate scaled by the percent of the trait variance that is explained by

376 individual loci (reflective of a scenario where selection acted solely on those loci), there was a

377 substantial increase in the area of the Normal Behaviour envelope. These changes to the

378 projected species distributions under climate change underscore the importance of incorporating

379 behavioural as well as physiological data into SDMs (Sunday, Bates, \& Dulvy, 2012), as well as

380 the key role that thermal trait evolution could play in range shifts (Buckley et al., 2010; Evans,

381 Diamond, \& Kelly, 2015; Lyon, Debinski, \& Rangwala, 2019).

382 Our models project a northward range expansion under climate change. This is

383 unsurprising because climate change opens newly available thermal niche space in waters north

384 of the current day geographic range (Alexander et al., 2018) (as is seen in the 'no evolution'

385 model northward expansion, Fig. 3b \& d). Northward range expansion with climate change due

386 to increasing habitat availability has also been documented in birds (Melles, Fortin, Lindsay, \&

387 Badzinski, 2011; Rushing, Andrew Royle, Ziolkowski, \& Pardieck, 2020; Tingley, Monahan,

388 Beissinger, \& Moritz, 2009; Tombre, Oudman, Shimmings, Griffin, \& Prop, 2019), plants 
(D’Andrea et al., 2009), other fishes (Fossheim et al., 2015; Spies et al., 2020; Yapıc1, Bilge, \&

390 Filiz, 2016), and pest species (such as ticks and mountain pine beetle, Clow et al., 2017; Kurz et

391 al., 2008; Ogden et al., 2006; Sagurova et al., 2019; Sambaraju, Carroll, \& Aukema, 2019), as

392 well as in large scale analyses of diverse taxa assessing the 'fingerprints' of climate change

393 impacts (Parmesan \& Yohe, 2003; Platts et al., 2019). What is perhaps less expected is that our

394 models reveal that cold tolerance can have a significant impact on predicted range distributions

395 under climate change, despite end-of-century climate change scenarios projecting an overall

396 warmer, not cooler world. However, climate change is leading to an increase in the frequency of

397 extreme temperature events (IPCC, 2014; Stott, 2016), including both extreme heat and extreme

398 cold (Herring et al., 2020, 2018, 2015), which could drive selection on both CTmin and CTmax

399 (Buckley \& Huey, 2016; Denny \& Dowd, 2012; Hoffman \& Sgrò, 2011; Kingsolver et al.,

400 2011). Moreover, although northern waters are warming on average, there has been considerable

401 spatial heterogeneity in temperature change in the recent past (Walther et al., 2002). Importantly,

402 northern waters are not predicted to be uniformly warmer under climate change (Alexander et al.,

403 2018; IPCC, 2014) relative to the southern waters in this range, especially when seasonal

404 variation is considered (Alexander et al., 2018). Seasonal variation and more extreme thermal

405 events under climate change scenarios may force organisms to respond independently to both

406 extreme heat and extreme cold in separate events (Herring et al., 2020, 2018, 2015; Walther et

407 al., 2002), and coupled with the functional correlation between CTmin and CTmax (as observed

408 here), population persistence will rely on adaptation in both upper and lower critical limits.

409 Further investigations to test the empirical rate of evolution of thermal behaviour, physiology

410 and the molecular underpinnings of these key traits would be well served by assessing additional 
411 subpopulations along the latitudinal gradient inhabited by stickleback to gain a more detailed

412 understanding of these temperature-associated traits over a wider environmental range.

413 In interpreting the projections we present here, it is important to note that we did not

414 extend the evolutionary rate of 0.63 haldanes to CTmax. Without an empirical estimate of the

415 rate of evolutionary change for CTmax in these populations or evidence for a physiologically

416 relevant boundary (as with CTmin not evolving lower than $0{ }^{\circ} \mathrm{C}$ ), extrapolating these parameters

417 to upper thermal limits would not be accurate. Nevertheless, there is a possibility that CTmax

418 could evolve at similar rates as CTmin, particularly in temperate marine ectotherms, given

419 similarities in genetic architecture and the correlation between these traits in this study.

420 However, there is a potential "hard limit" to upper thermal tolerance, as seen in tropical marine

421 ectotherms, and CTmax evolution can also be a slow process, as seen in some terrestrial systems

422 (Morgan, Finnøen, Jensen, Pélabon, \& Jutfelt, 2021). Ultimately, given the overall warming that

423 is projected for marine systems by the end-of-century (IPCC, 2014, 2018), there is a critical need

424 for empirical measures of CTmax evolutionary rates for predicting future species distributions.

425 The efficiency of translating the selection acting on a trait into evolutionary response

426 across generations will depend on the genetic architecture of the trait and the extent of

427 environmental change (Rogers et al., 2012). The empirical rate of CTmin evolution in

428 sticklebacks that we incorporated into our SDMs was estimated using change in phenotypic

429 variation across generations (Barrett et al., 2011), rather than evolution at underlying loci. As

430 such, it is likely that some proportion of the observed phenotypic change was due to plastic

431 responses. In our scaled evolution models, we took a conservative approach by restricting

432 phenotypic evolution to only occur through heritable change via the loci shown to be associated

433 with the trait. The large effect loci that we identified here are consistent with expectations from 
434 theory that suggest prolonged bouts of adaptation with gene flow (as expected in this system,

435 Jones, Chan, et al., 2012; Rogers et al., 2012; Schluter, Marchinko, Barrett, \& Rogers, 2010) will

436 favour architectures characterized by fewer, larger effect, more tightly linked alleles (Via, Conte,

437 Mason-Foley, \& Mills, 2012; Yeaman \& Otto, 2011; Yeaman \& Whitlock, 2011). However, the

438 effects of the QTL identified from these populations are likely overestimated, while other loci

439 may have gone undetected (sensu the Beavis Effect, Beavis, 1994). Overall, the joint action of

440 plastic effects and evolution at undetected loci might therefore result in range distributions that

441 are more similar to those projected in our 'evolution' models.

442 Collectively, the inclusion of thermal traits and their evolution alters the projected ranges

443 of marine threespine stickleback, with a substantial increase in the projected area that the species

444 will occupy under climate change forecasts. Many traits are evolving in response to climate

445 change (Eliason et al., 2011; Gómez-Ruiz \& Lacher, 2019; Horton et al., 2020; Hovel, Carlson,

446 \& Quinn, 2016) and SDMs that do not take trait data (and trait evolution) into account could

447 provide less accurate predictions about future species distributions under climate change (Bush et

448 al., 2016; Guisan et al., 2013; Huey et al., 2012; Kearney \& Porter, 2004) - an issue of particular

449 concern for species at risk and pest species undergoing range expansion (Bebber, 2015;

450 Cullingham et al., 2011; McLeod, Hallegraeff, Hosie, \& Richardson, 2012). Our results provide

451 a framework for addressing this problem, which will have critical implications for the application

452 of these models in policy, sustainable resource management, and the protection of biodiversity in 453 a changing climate.

455 References

456 Alexander, M. A., Scott, J. D., Friedland, K. D., Mills, K. E., Nye, J. A., Pershing, A. J., \&

457 Thomas, A. C. (2018). Projected sea surface temperatures over the 21st century: Changes in 
the mean, variability and extremes for large marine ecosystem regions of Northern Oceans. Elementa, 6. doi: 10.1525/elementa.191

Arends, D., Prins, P., Broman, K. W., \& Jansen, R. C. (2014). Tutorial-Multiple-QTL Mapping

Barrett, R., \& Hendry, A. (2012). Evolutionary rescue under environmental change. In Behavioural responses to a changing world: mechanisms and consequences (pp. 216-233). Oxford University Press Oxford, UK.

Barrett, R., Paccard, A., Healy, T., Bergek, S., Schulte, P., Schluter, D., \& Rogers, S. (2011). Rapid evolution of cold tolerance in stickleback. Proceedings of Royal Society B, 278(1703), 233-238. doi: 10.1098/rspb.2010.0923

Bayly, I. A. E. (2003). Salinity Tolerance and Osmotic Behavior of Animals in Athalassic Saline and Marine Hypersaline Waters. Annual Review of Ecology and Systematics, 3(1), 233-268. doi: 10.1146/annurev.es.03.110172.001313

Beavis, W. (1994). The power and deceit of QTL experiments: lessons from comparative QTL

Bebber, D. P. (2015). Range-Expanding Pests and Pathogens in a Warming World. Annual

Beitinger, T., Bennett, W., \& McCauley, R. (2000). Temperature tolerances of North American freshwater fishes exposed to dynamic changes in temperature. Environmental Biology of Fishes, 58, 237-275. doi: 10.1023/A:1007676325825

478 Broman, K. W., \& Sen, S. (2009). A Guide to QTL Mapping with R/qtl (Vol. 46). Springer.

479 Broman, K. W., Wu, H., Sen, Ś., \& Churchill, G. A. (2003). R/qtl: QTL mapping in experimental crosses. Bioinformatics, 19(7), 889-890. doi: 10.1093/bioinformatics/btg112

Buckley, L., \& Huey, R. (2016). How extreme temperatures impact organisms and the evolution of their thermal tolerance. Integrative and Comparative Biology, 56(1), 98-109. doi: 10.1093/icb/icw004

Buckley, L., Urban, M., Angilletta, M., Crozier, L., Rissler, L., \& MW, S. (2010). Can mechanism inform species' distribution models? Ecology Letters, 13, 1041-1054. doi: 10.1111/j.1461-0248.2010.01479.x

491 Catchen, J., Hohenlohe, P. A., Bassham, S., Amores, A., \& Cresko, W. A. (2013). Stacks: An analysis tool set for population genomics. Molecular Ecology, 22(11), 3124-3140. doi: $10.1111 / \mathrm{mec} .12354$ 
494

Cheng, C. H. C., \& Detrich, H. W. (2007). Molecular ecophysiology of Antarctic notothenioid fishes. Philosophical Transactions of the Royal Society B: Biological Sciences, 362(1488), 2215-2232. doi: 10.1098/rstb.2006.1946

Clow, K. M., Leighton, P. A., Ogden, N. H., Lindsay, L. R., Michel, P., Pearl, D. L., \& Jardine, C. M. (2017). Northward range expansion of Ixodes scapularis evident over a short timescale in Ontario, Canada. PLoS ONE, 12(12), 1-15. doi: 10.1371/journal.pone.0189393

Cooper, B., Adriaenssens, B., \& Killen, S. S. (2018). Individual variation in the compromise between social group membership and exposure to preferred temperatures. Proceedings of the Royal Society B: Biological Sciences, 285(1880). doi: 10.1098/rspb.2018.0884

Coutant, C. C. (1987). Thermal preference: when does an asset become a liability? Environmental Biology of Fishes, 18(5), 161-172. doi: 10.1007/BF00000356

Cullingham, C. I., Cooke, J. E. K., Dang, S., Davis, C. S., Cooke, B. J., \& Coltman, D. W. (2011). Mountain pine beetle host-range expansion threatens the boreal forest. Molecular Ecology, 20(10), 2157-2171. doi: 10.1111/j.1365-294X.2011.05086.x

D’Andrea, L., Broennimann, O., Kozlowski, G., Guisan, A., Morin, X., Keller-Senften, J., \& Felber, F. (2009). Climate change, anthropogenic disturbance and the northward range expansion of Lactuca serriola (Asteraceae). Journal of Biogeography, 36(8), 1573-1587. doi: $10.1111 / \mathrm{j} .1365-2699.2008 .02060 . \mathrm{x}$

Danecek, P., Auton, A., Abecasis, G., Albers, C. A., Banks, E., DePristo, M. A., ... Group, 1000 Genomes Project Analysis. (2011). The variant call format and VCFtools. Bioinformatics, 27(15), 2156-2158. doi: 10.1093/bioinformatics/btr330

Denny, M. W., \& Dowd, W. W. (2012). Biophysics, environmental stochasticity, and the evolution of thermal safety margins in intertidal limpets. Journal of Experimental Biology, 215(6), 934-947. doi: 10.1242/jeb.058958

Detrich, H. W., Parker, S. K., Williams, J., Nogales, E., \& Downing, K. H. (2000). Cold adaptation of microtubule assembly and dynamics. Structural interpretation of primary sequence changes present in the $\alpha$ - and $\beta$-tubulins of antarctic fishes. Journal of Biological Chemistry, 275(47), 37038-37047. doi: 10.1074/jbc.M005699200

Divino, J. N., Monette, M. Y., McCormick, S. D., Yancey, P. H., Flannery, K. G., Bell, M. A., ... Schultz, E. T. (2016). Osmoregulatory physiology and rapid evolution of salinity tolerance in threespine stickleback recently introduced to fresh water. Evolutionary Ecology Research, 17(2), 179-201.

Eliason, E. J., Clark, T. D., Hague, M. J., Hanson, L. M., Gallagher, Z. S., Jeffries, K. M., ... Farrell, A. P. (2011). Differences in thermal tolerance among sockeye salmon populations. Science, 332(6025), 109-112. doi: 10.1126/science.1199158

Environmental Systems Research Institute. (2017). ArcGIS Desktop: Release 10.8. Redlands, CA. 
Evans, T. G., Diamond, S. E., \& Kelly, M. W. (2015). Mechanistic species distribution modelling as a link between physiology and conservation. Conservation Physiology, 3(1), 1-16. doi: 10.1093/conphys/cov056

Eyer, P. A., Blumenfeld, A. J., \& Vargo, E. L. (2019). Sexually antagonistic selection promotes genetic divergence between males and females in an ant. Proceedings of the National Academy of Sciences of the United States of America, 116(48), 24157-24163. doi: 10.1073/pnas.1906568116

Fangue, N. A., Hofmeister, M., \& Schulte, P. M. (2006). Intraspecific variation in thermal tolerance and heat shock protein gene expression in common killifish, Fundulus heteroclitus. The Journal of Experimental Biology, 209(15), 2859-2872. doi: $10.1242 /$ jeb.02260

Fetterer, F., Savoie, M., Helfrich, S., \& Clemene-Colon, P. (2010). U.S. National Ice Center and National Snow and Ice Data Center. Multisensor Analyzed Sea Ice Extent - Northern Hemisphere (MASIE-NH). Boulder, Colorado, USA: NSIDC: National Snow and Ice Data Center. doi: https://doi.org/10.7265/N5GT5K3K.

Fossheim, M., Primicerio, R., Johannesen, E., Ingvaldsen, R. B., Aschan, M. M., \& Dolgov, A. V. (2015). Recent warming leads to a rapid borealization of fish communities in the Arctic. Nature Climate Change, 5(7), 673-677. doi: 10.1038/nclimate2647

Gómez-Ruiz, E. P., \& Lacher, T. E. (2019). Climate change, range shifts, and the disruption of a pollinator-plant complex. Scientific Reports, 9(1), 1-10. doi: 10.1038/s41598-019-53670-9

Greenwood, A. K., Jones, F. C., Chan, Y. F., Brady, S. D., Absher, D. M., Grimwood, J., ... Peichel, C. L. (2011). The genetic basis of divergent pigment patterns in juvenile threespine sticklebacks. Heredity, 107(2), 155-166. doi: 10.1038/hdy.2011.1

Guisan, A., Tingley, R., Baumgartner, J. B., Naujokaitis-Lewis, I., Sutcliffe, P. R., Tulloch, A. I. T., ... Buckley, Y. M. (2013). Predicting species distributions for conservation decisions. Ecology Letters, 16(12), 1424-1435. doi: 10.1111/ele.12189

Harrell, F. (2014). Hmisc: Harrell Miscellaneous. 2014.

Hendry, A. P., Peichel, C. L., Matthews, B., Boughman, J. W., \& Nosil, P. (2013). Stickleback research: The now and the next. Evolutionary Ecology Research, 15(2), 111-141.

Herring, S., Christidis, N., Hoell, A., Hoerling, M., \& Stott, P. (2020). Explaining extreme events of 2018 from a climate perspective. Bulletin of the American Meteorological Society, 101(1), 1-146. doi: 10.1175/1520-0477-95.9.s1.1

Herring, S., Christidis, N., Hoell, A., Kossin, J., Schreck, C., \& Stott, P. (2018). Explaining extreme events of 2016 from a climate perspective. Bulletin of the American Meteorological Society, 99(1), S1-S157. Retrieved from https://journals.ametsoc.org/view/journals/bams/99/1/bamsexplainingextremeevents2016.1.xml 
Herring, S., Hoerling, M., Kossing, J., Peterson, T., \& Stott, P. (2015). Explaining extreme events of 2014 from a climate perspective. 96(12), 1-180.

Hijmans, R. J., Etten, J. van, Sumner, M., Cheng, J., Bevan, A., Bevan, R., ... Greenberg, J. A. (2020). raster: Geographic data analysis and modelling. Retrieved from https://cran.rproject.org/web/packages/raster/raster.pdf

Hochachka, P. W., \& Somero, G. N. (2002). Mechanism and process in physiological evolution. Biochemical Adaptation, 480.

Hoffman, A., \& Sgrò, C. (2011). Climate change and evolutionary adaptation. Nature, 470, 479_ 485.

Horton, K. G., La Sorte, F. A., Sheldon, D., Lin, T. Y., Winner, K., Bernstein, G., ... continental scale. Nature Climate Change, 10(1), 63-68. doi: 10.1038/s41558-019-0648-9

Hovel, R. A., Carlson, S. M., \& Quinn, T. P. (2016). Climate change alters the reproductive phenology and investment of a lacustrine fish, the three-spine stickleback. Global Change Biology, 1-13. doi: 10.1111/gcb.13531

Hu, D., Guan, Z., Tian, W., \& Ren, R. (2018). Recent strengthening of the stratospheric Arctic vortex response to warming in the central North Pacific. Nature Communications, 9(1). doi: $10.1038 / \mathrm{s} 41467-018-04138-3$

Huey, R. B., Kearney, M. R., Krockenberger, A., Holtum, J. A. M., Jess, M., \& Wiliams, S. E. (2012). Predicting organismal vulnerability to climate warming: roles of behaviour, physiology and adaptation. Philosophical Transactions of the Royal Society B: Biological Sciences, 367, 1665-1679. doi: 10.1098/rstb.2012.0005

Huey, R. B., \& Kingsolver, J. G. (1989). Evolution of thermal sensitivity of ectotherm performance. Trends in Ecology and Evolution, 4(5), 131-135.

Huey, R. B., \& Kingsolver, J. G. (2011). Variation in universal temperature dependence of biological rates. Proceedings of the National Academy of Sciences of the United States of America, 108(26), 10377-10378. doi: 10.1073/pnas.1107430108

Huey, R. B., \& Slatkin, M. (1976). Costs and benefits of lizard thermoregulation. Quarterly Review of Biology, 51(3), 363-384.

Hutchison, V. H. (1961). Comparative Biology Critical Thermal Maxima in Salamanders. Physiological Zoology, 34(2), 92-125.

IPCC. (2014). Climate Change 2014: Synthesis Report. In Fifth Assessment Report of the Intergovernmental Panel on Climate Change. doi: 10.1016/S0022-0248(00)00575-3

IPCC. (2018). IPCC special report on the impacts of global warming of $1.5^{\circ} \mathrm{C}$ - Summary for policy makers. (October 2018). Retrieved from http://www.ipcc.ch/report/sr15/ 
603

604

605

606

607

608

609

610

611

612

613

614

615

616

617

618

619

620

621

622

623

624

625

626

627

628

629

630

631

632

633

634

635

636

637

638

639

Johannessen, O., Bengtsson, L., Miles, M., Nagurnyi, A., Zakharov, V., Bobylev, L., ... Cattle, H. (2004). Arctic climate change: observed and modelled temperature and sea-ice variability. Tellus A: Dynamic Meteorology and Oceanography, 56(4), 328-341. doi: 10.3402/tellusa.v56i4.14418

Jones, F. C., Chan, Y. F., Schmutz, J., Grimwood, J., Brady, S. D., Southwick, A. M., ... Kingsley, D. M. (2012). A genome-wide SNP genotyping array reveals patterns of global and repeated species-pair divergence in sticklebacks. Current Biology, 22(1), 83-90. doi: 10.1016/j.cub.2011.11.045

Jones, F. C., Grabherr, M. G., Chan, Y. F., Russell, P., Mauceli, E., Johnson, J., ... Kingsley, D. M. (2012). The genomic basis of adaptive evolution in threespine sticklebacks. Nature, 484(7392), 55-61. doi: 10.1038/nature10944

Kearney, M., \& Porter, W. (2009). Mechanistic niche modelling: Combining physiological and spatial data to predict species' ranges. Ecology Letters, 12(4), 334-350. doi: 10.1111/j.1461-0248.2008.01277.x

Kearney, M., \& Porter, W. P. (2004). Mapping the fundamental niche: Physiology, climate, and the distribution of a nocturnal lizard. Ecology, 85(11), 3119-3131. doi: 10.1890/03-0820

Kingsolver, J. G., Arthur Woods, H., Buckley, L. B., Potter, K. A., MacLean, H. J., \& Higgins, J. K. (2011). Complex life cycles and the responses of insects to climate change. Integrative and Comparative Biology, 51(5), 719-732. doi: 10.1093/icb/icr015

Kirch, M., Romundset, A., Gilbert, M. T. P., Jones, F. C., \& Foote, A. D. (2021). Ancient and modern stickleback genomes reveal the demographic constraints on adaptation. Current Biology, 31(9), 2027-2036.e8. doi: 10.1016/j.cub.2021.02.027

Kurz, W. A., Dymond, C. C., Stinson, G., Rampley, G. J., Neilson, E. T., Carroll, A. L., ... Safranyik, L. (2008). Mountain pine beetle and forest carbon feedback to climate change. Nature, 452(7190), 987-990. doi: 10.1038/nature06777

Li, H., \& Durbin, R. (2010). Fast and accurate long-read alignment with Burrows-Wheeler transform. Bioinformatics, 26(5), 589-595. doi: 10.1093/bioinformatics/btp698

Lyon, N. J., Debinski, D. M., \& Rangwala, I. (2019). Evaluating the Utility of Species Distribution Models in Informing Climate Change-Resilient Grassland Restoration Strategy. Frontiers in Ecology and Evolution, 7(February), 1-8. doi: 10.3389/fevo.2019.00033

McLeod, D. J., Hallegraeff, G. M., Hosie, G. W., \& Richardson, A. J. (2012). Climate-driven range expansion of the red-tide dinoflagellate Noctiluca scintillans into the Southern Ocean. Journal of Plankton Research, 34(4), 332-337. doi: 10.1093/plankt/fbr112

Melles, S. J., Fortin, M. J., Lindsay, K., \& Badzinski, D. (2011). Expanding northward: Influence of climate change, forest connectivity, and population processes on a threatened species' range shift. Global Change Biology, 17(1), 17-31. doi: 10.1111/j.1365-2486.2010.02214.x

Morgan, R., Finnøen, M. H., Jensen, H., Pélabon, C., \& Jutfelt, F. (2021). Low potential for 
evolutionary rescue from climate change in a tropical fish. Proceedings of the National Academy of Sciences of the United States of America, 117(52), 33365-33372. doi: 10.1073/PNAS.2011419117

Morris, M. R. J., Bowles, E., Allen, B. E., Jamniczky, H. A., \& Rogers, S. M. (2018). Contemporary ancestor? Adaptive divergence from standing genetic variation in Pacific marine threespine stickleback. BMC Evolutionary Biology, 18(1), 1-21. doi: $10.1186 / \mathrm{s} 12862-018-1228-8$

Ogden, N. H., Maarouf, A., Barker, I. K., Bigras-Poulin, M., Lindsay, L. R., Morshed, M. G., ... Charron, D. F. (2006). Climate change and the potential for range expansion of the Lyme disease vector Ixodes scapularis in Canada. International Journal for Parasitology, 36(1), 63-70. doi: 10.1016/j.ijpara.2005.08.016

Ouellette, L. A., Reid, R. W., Blanchard, S. G., \& Brouwer, C. R. (2018). LinkageMapViewrendering high-resolution linkage and QTL maps. Bioinformatics, 34(2), 306-307. doi: 10.1093/bioinformatics/btx576

Parmesan, C., \& Yohe, G. (2003). A globally coherent fingerprint of climate change impacts across natural systems. 421, 37-42. doi: 10.1038/nature01286

Peterson, B. K., Weber, J. N., Kay, E. H., Fisher, H. S., \& Hoekstra, H. E. (2012). Double digest RADseq: An inexpensive method for de novo SNP discovery and genotyping in model and non-model species. PLoS ONE, 7(5). doi: 10.1371/journal.pone.0037135

Platts, P. J., Mason, S. C., Palmer, G., Hill, J. K., Oliver, T. H., Powney, G. D., ... Thomas, C. D. (2019). Habitat availability explains variation in climate-driven range shifts across multiple taxonomic groups. Scientific Reports, 9(1), 1-10. doi: 10.1038/s41598-019-51582-2

Puritz, J. B., Hollenbeck, C. M., \& Gold, J. R. (2014). dDocent $\square$ : a RADseq, variant-calling pipeline designed for population genomics of non-model organisms. PeerJ, 2, e431. doi: 10.7717/peerj.431

R Core Team. (2019). R: A language and environment for statistical computing.

Rastas, P. (2017). Lep-MAP3: Robust linkage mapping even for low-coverage whole genome sequencing data. Bioinformatics, 33(23), 3726-3732. doi: 10.1093/bioinformatics/btx494

Reynolds, R., Smith, T., Liu, C., Chelton, D., Casey, K., \& Schlax, M. (2007). Daily HighResolution-Blended Analyses for Sea Surface Temperature. Journal of Climate, 20(22), 5473-5496. doi: 10.1175/2007jcli1824.1

Roger, A., Stuetz, R., Ove, K., Giraudoux, P., \& Santilli, S. (2020). rgeos: Interface to geometry engine - open.

Rogers, S. M., Tamkee, P., Summers, B., Balabahadra, S., Marks, M., Kingsley, D. M., \& Schluter, D. (2012). Genetic Signature of Adaptive Peak Shift in Threespine Stickleback. Evolution, (Fisher 1930), 2439-2451. doi: 10.5061/dryad.6jj614kh 
676

677

678

679

680

681

682

683

684

685

686

687

688

689

690

691

692

693

694

695

696

697

698

699

700

701

702

703

704

705

706

707

708

709

710

711

712

713

Rushing, C. S., Andrew Royle, J., Ziolkowski, D. J., \& Pardieck, K. L. (2020). Migratory behavior and winter geography drive differential range shifts of eastern birds in response to recent climate change. Proceedings of the National Academy of Sciences of the United States of America, 117(23), 12897-12903. doi: 10.1073/pnas.2000299117

Sagurova, I., Ludwig, A., Ogden, N. H., Pelcat, Y., Dueymes, G., \& Gachon, P. (2019). Predicted northward expansion of the geographic range of the tick vector amblyomma americanum in North America under future climate conditions. Environmental Health Perspectives, 127(10), 1-14. doi: 10.1289/EHP5668

Sambaraju, K. R., Carroll, A. L., \& Aukema, B. H. (2019). Multiyear weather anomalies associated with range shifts by the mountain pine beetle preceding large epidemics. Forest Ecology and Management, 438(September 2018), 86-95. doi: 10.1016/j.foreco.2019.02.011

Schluter, D., Marchinko, K., Barrett, R., \& Rogers, S. (2010). Natural selection and the genetics of adaptation in threespine stickleback. Philosophical Transactions of the Royal Society B: Biological Sciences, 365(1552), 2479-2486. doi: 10.1098/rstb.2010.0036

Sexton, J. P., McIntyre, P. J., Angert, A. L., \& Rice, K. J. (2009). Evolution and Ecology of Species Range Limits. Annual Review of Ecology, Evolution, and Systematics, 40(1), 415436. doi: 10.1146/annurev.ecolsys.110308.120317

Shin, S. C. hu., Ahn, D. H. wa., Kim, S. J. i., Pyo, C. W. o., Lee, H., Kim, M. K., ... Park, H. (2014). The genome sequence of the Antarctic bullhead notothen reveals evolutionary adaptations to a cold environment. Genome Biology, 15(9), 468. doi: 10.1186/s13059-0140468-1

Spies, I., Gruenthal, K. M., Drinan, D. P., Hollowed, A. B., Stevenson, D. E., Tarpey, C. M., \& Hauser, L. (2020). Genetic evidence of a northward range expansion in the eastern Bering Sea stock of Pacific cod. Evolutionary Applications, 13(2), 362-375. doi: 10.1111/eva.12874

Stott, P. (2016). How climate change affects extreme weather events. Science, 352(6293), 15171518. doi: $10.1126 /$ science.aaf7271

Sunday, J. M., Bates, A. E., \& Dulvy, N. K. (2012). Thermal tolerance and the global redistribution of animals. Nature Climate Change, 2(9), 686-690. doi: 10.1038/nclimate1539

Tingley, M. W., Monahan, W. B., Beissinger, S. R., \& Moritz, C. (2009). Birds track their Grinnellian niche through a century of climate change. Proceedings of the National Academy of Sciences of the United States of America, 106(SUPPL. 2), 19637-19643. doi: 10.1073/pnas.0901562106

Tombre, I. M., Oudman, T., Shimmings, P., Griffin, L., \& Prop, J. (2019). Northward range expansion in spring-staging barnacle geese is a response to climate change and population growth, mediated by individual experience. Global Change Biology, 25(11), 3680-3693. doi: $10.1111 / \mathrm{gcb} .14793$ 
Via, S., Conte, G., Mason-Foley, C., \& Mills, K. (2012). Localizing FST outliers on a QTL map reveals evidence for large genomic regions of reduced gene exchange during speciationwith-gene-flow. Molecular Ecology, 21(22), 5546-5560. doi: 10.1111/mec.12021

Weatherall, P., Marks, K., Jakobsson, M., Schmitt, T., Tani, S., Arndt, J., ... Wigley, R. (2015).

Wei, T., Simko, V., Levy, M., Xie, Y., Jin, Y., \& Zemla, J. (2017). Package 'corrplot.' Statistician, 56, 316-324.

Wiens, J., Stralberg, D., Jongsomjit, D., Howell, C., \& Snyder, M. (2009). Niches, models, and climate change: Assessing the assumptions and uncertainties. Proceedings of the National Academy of Sciences, 106(Supplement_2), 19729-19736. doi: 10.1073/pnas.0901639106

Yapıc1, S., Bilge, G., \& Filiz, H. (2016). Northwards range expansion of Sparisoma cretense (Linnaeus, 1758) in the Turkish Aegean Sea. Journal of Aquaculture Engineering and Fisheries Research, (August), 201-207. doi: 10.3153/jaefr16022

Yeaman, S., \& Otto, S. P. (2011). Establishment and maintenance of adaptive genetic divergence under migration, selection, and drift. Evolution, 65(7), 2123-2129. doi: 10.1111/j.15585646.2011.01277.x

Yeaman, S., \& Whitlock, M. C. (2011). The genetic architecture of adaptation under migrationselection balance. Evolution, 65(7), 1897-1911. doi: 10.1111/j.1558-5646.2011.01269.x

Zeidberg, L. D., \& Robison, B. H. (2007). Invasive range expansion by the Humboldt squid, Dosidicus gigas, in the eastern North Pacific. Proceedings of the National Academy of Sciences, 104(31), 12948-12950. doi: 10.1073/pnas.0702043104

Zweng, M. M., Reagan, J. R., Antonov, J. I., Mishonov, A. V., Boyer, T. P., Garcia, H. E., ... Bidlle, M. M. (2013). World Ocean Atlas 2013, Volume 2: Salinity. In NOAA Atlas NESDIS 74 (Vol. 2). doi: 10.1182/blood-2011-06-357442

Acknowledgments

744 The authors acknowledge that the species collections took place on Huu-ay-aht and Sechelt First

745 Nations traditional territories and are grateful for the opportunity to conduct their research in

746 protected and sacred areas. We would like to thank the Bamfield Marine Sciences Centre for the

747 resources required to conduct this research, Sam Owens for the photo in Figure 1a, Peter Peller 
748 for creating Figure 1b, as well as Daniel Wuitchik, Sam Yeaman, Jennifer Sunday, and Patrick

749 Nosil for feedback on the manuscript. This research was funded by Discovery Grants from the

750 Natural Sciences and Engineering Research Council of Canada to RDHB and SMR, a Canada

751 Research Chair to RDHB, a New Faculty Award from Alberta Innovates Technology Futures to

752 SMR.

\section{Author Contributions}

754 This study was designed by SJSW, RDHB, and SMR; fish husbandry and breeding by SJSW and

755 TNB; experimental data collection by SJSW; DNA sequencing and initial processing by AP;

756 bioinformatic and QTL analyses by SJSW; species distribution modelling by SJSW and SM; the

757 manuscript was written by SJSW, RDHB, and SMR, with input from authors; the study was

758 funded by HAJ, RDHB, and SMR.

759 Data Accessibility

760 The data associated with this work is available as follows:

761 DNA sequences: upload pending on NCBI SRA

762 Experimental data associated with thermal trait data: available on Dryad

763 (https://doi.org/10.5061/dryad.70rxwdbz6)

764 Annotated code and example files: available on Github

765 (https://github.com/sjswuitchik/gasAcu_qtl_sdm) 
a)

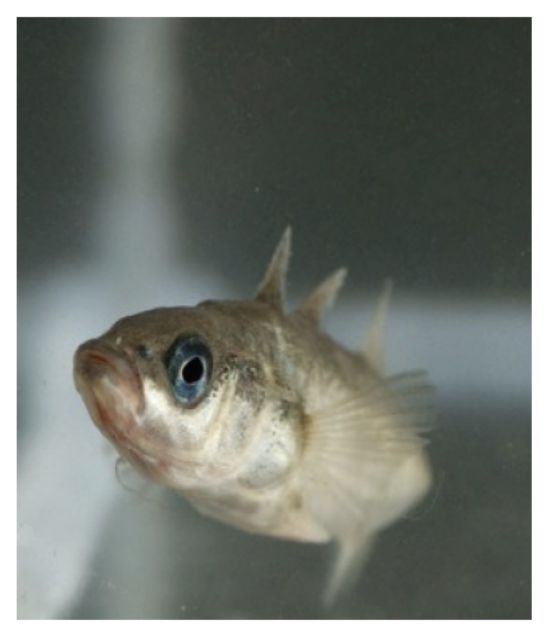

b)

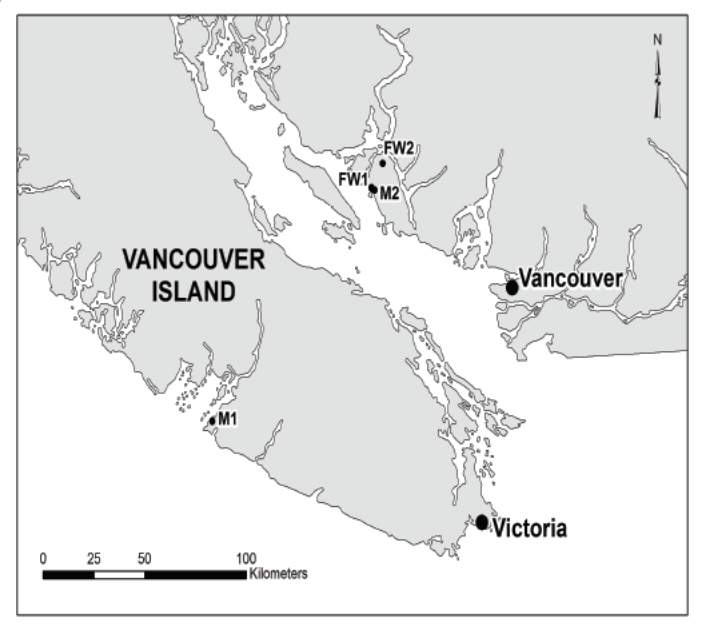

c)

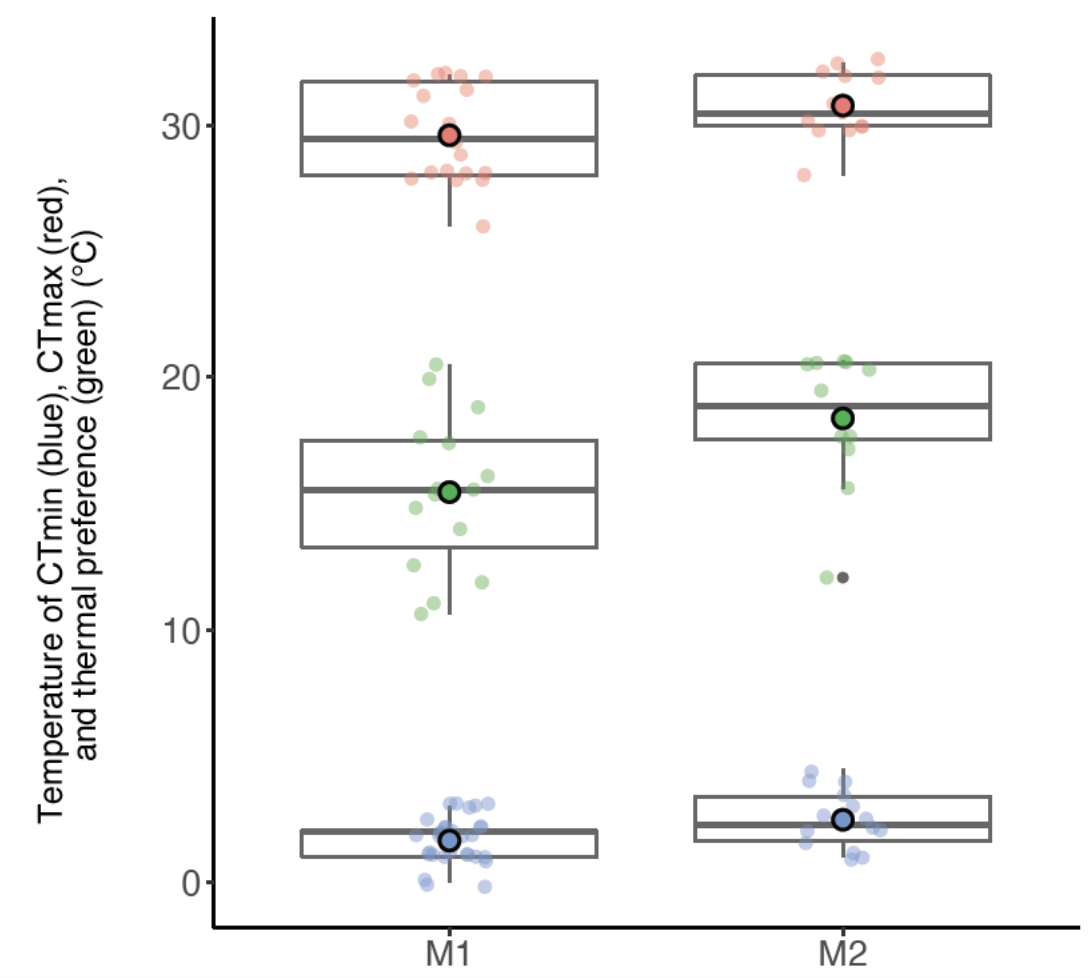

Figure 1. a) Adult threespine stickleback (Gasterosteus aculeatus) from a single genetic cluster were sampled from b) two marine and two freshwater populations in the Canadian Pacific Northwest. These populations were assayed for c) thermal preference (green), critical thermal minima (blue) and maxima (red). Thermal trait values for marine populations (M1 and M2) were incorporated into the species distribution models, while marine and freshwater populations (M1, FW1, and FW2) were used to generate F1 and F2 generations for linkage map construction and quantitative trait loci (QTL) analyses. 


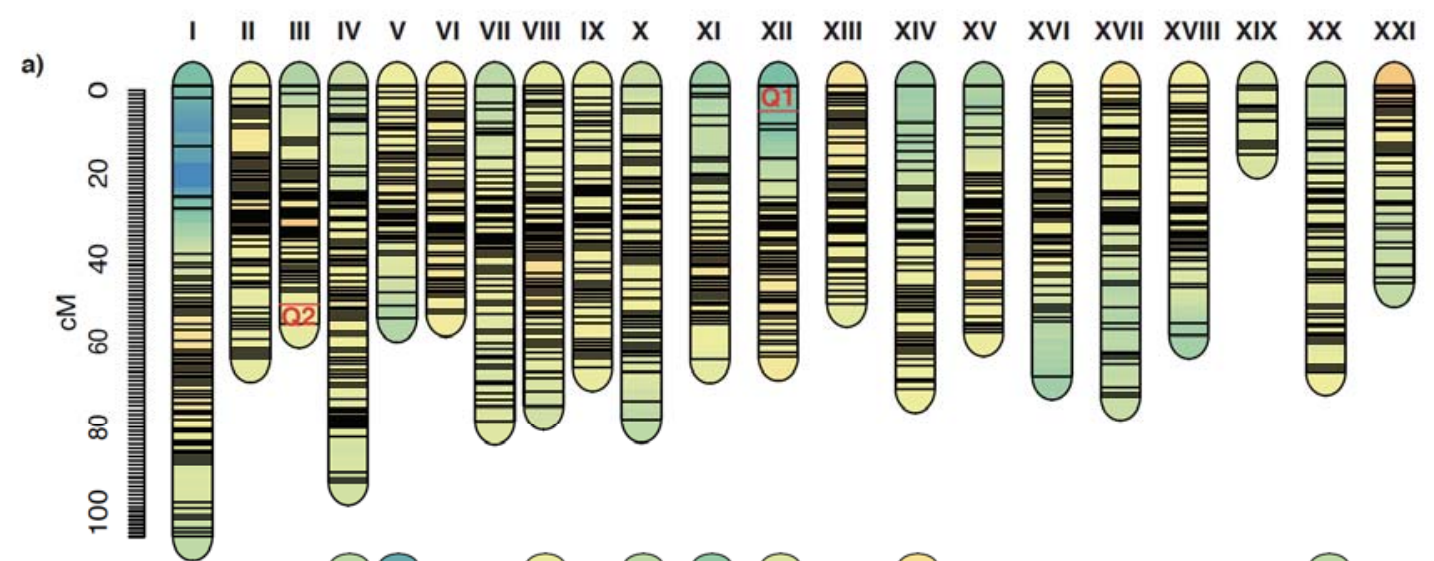

b)
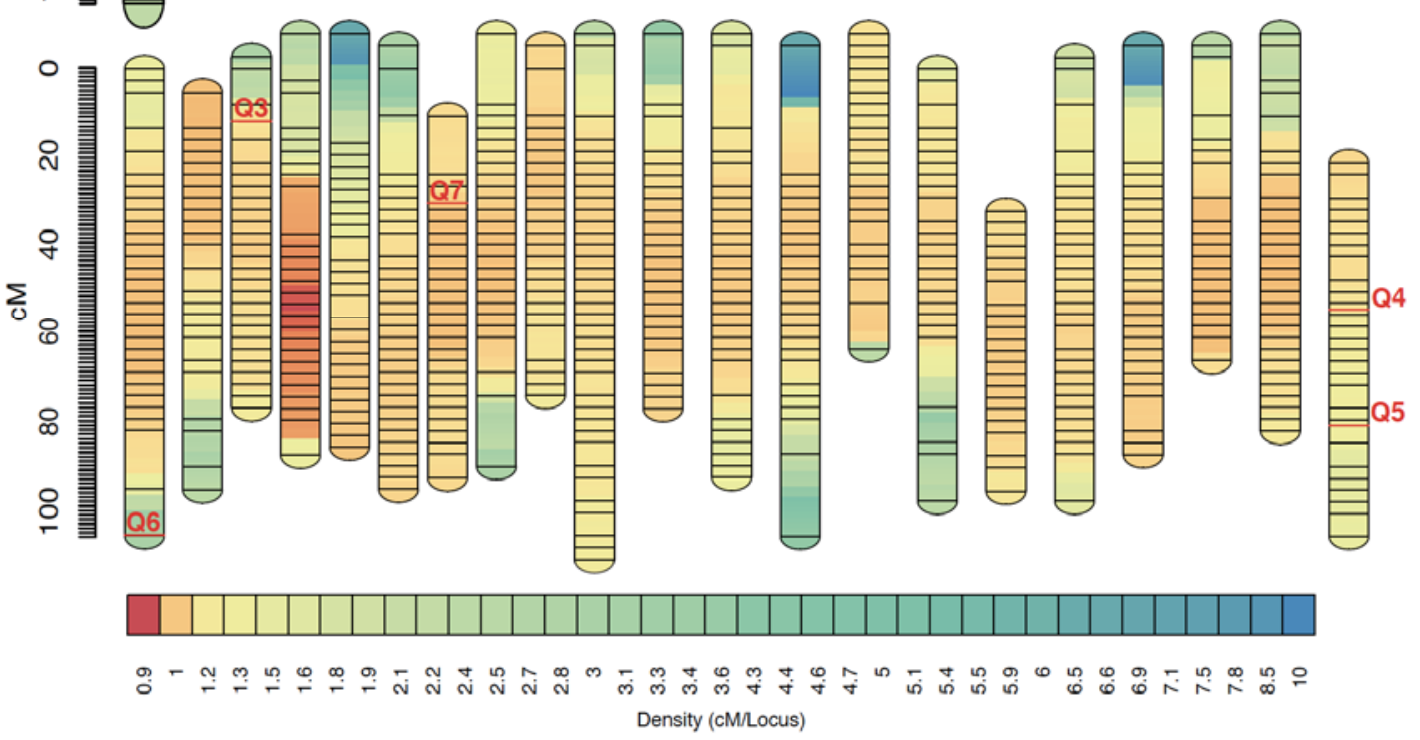

Figure 2. Linkage maps constructed for quantitative trait loci (QTL) analyses for a) H1 F2 hybrids (M1 x FW1) and b) H2 F2 hybrids

778 (M1 x FW2) families, rendered with LinkageMapView (Ouellette, Reid, Blanchard, \& Brouwer, 2018), with locations of QTL

779 indicated (Table 1). 


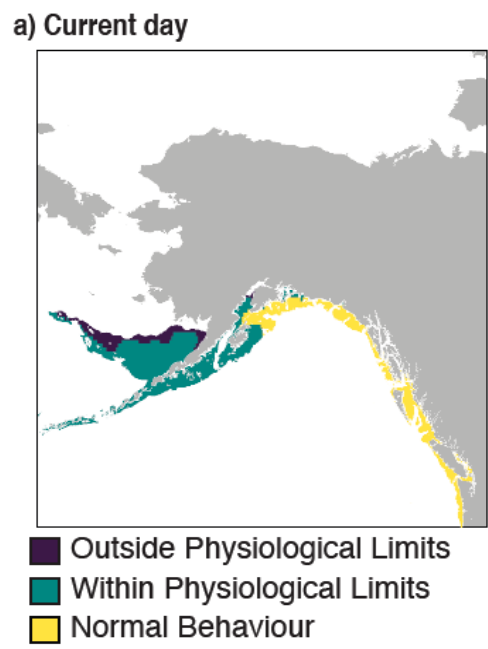

781
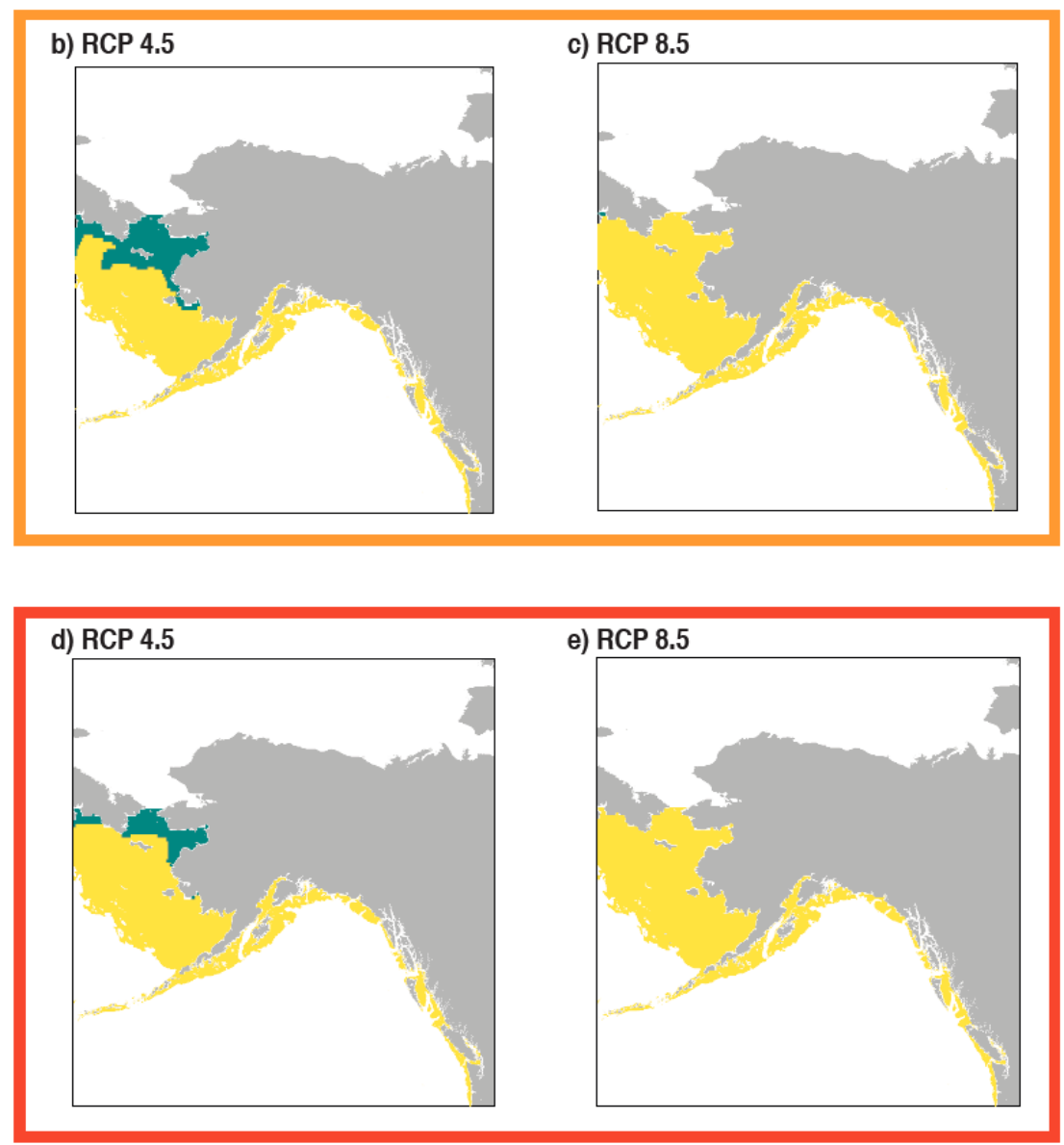

Figure 3. Changes in the projected distribution of marine threespine stickleback (Gasterosteus aculeatus) as a result of incorporating thermal traits into models of current day environmental conditions (a) and under IPCC end-of-century projections RCP 4.5 and 8.5, either without trait evolution (b \& c; 'no evolution' model, orange box) and with trait evolution (d \& e; 'evolution' model, red box). 
Table 1. Significant quantitative trait loci (QTL) for critical thermal minimum (CTmin), critical thermal maximum (CTmax), and thermal preference (Preference) traits with the percent of trait variance explained (PVE) for each QTL, the logarithm of odds (LOD) threshold for significance, and the LOD peak observed for each QTL.

\begin{tabular}{|l|l|l|l|r|r|r|r|}
\hline QTL Name & Family & Phenotype & Linkage Group & Position & PVE (\%) & \multicolumn{2}{l|}{$\begin{array}{l}\text { LOD threshold } \\
(5 \%)\end{array}$} \\
\hline Q1 & H1_F2 & CTmax & XII & 4.56 & 45.2 & 2.71 \\
\hline Q2 & H1_F2 & Preference & III & 50.04 & 53.3 & 2.78 \\
\hline Q3 & H2_F2_1 & CTmin & III & 11.57 & 28.9 & 2.57 \\
\hline Q4 & H2_F2_2 & CTmin & XXI & peak & 3.64 \\
\hline Q6 & H2_F2_2 & CTmax & XXI & 55.67 & 53.7 & 2.63 \\
\hline Q7 & H2_F2_2 & Preference & I & 81.36 & 83.3 & 5.75 & 5.57 \\
\hline
\end{tabular}




\section{Supplementary Figures and Tables}

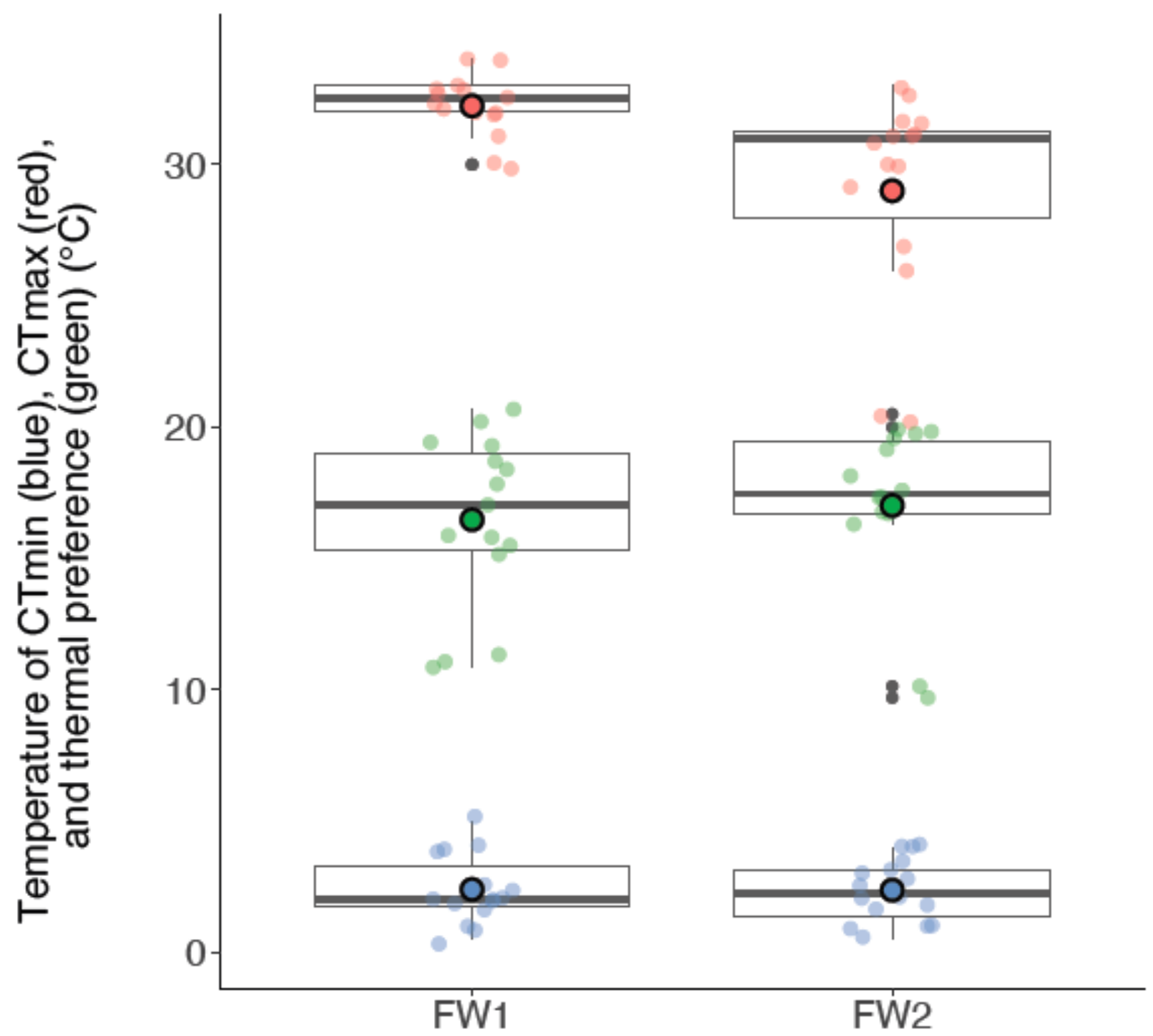

792 Figure S1. Thermal preference (green), critical thermal minimum (blue) and maximum 793 (red) measurements for adult threespine stickleback (Gasterosteus aculeatus) from wild 794 freshwater populations. 


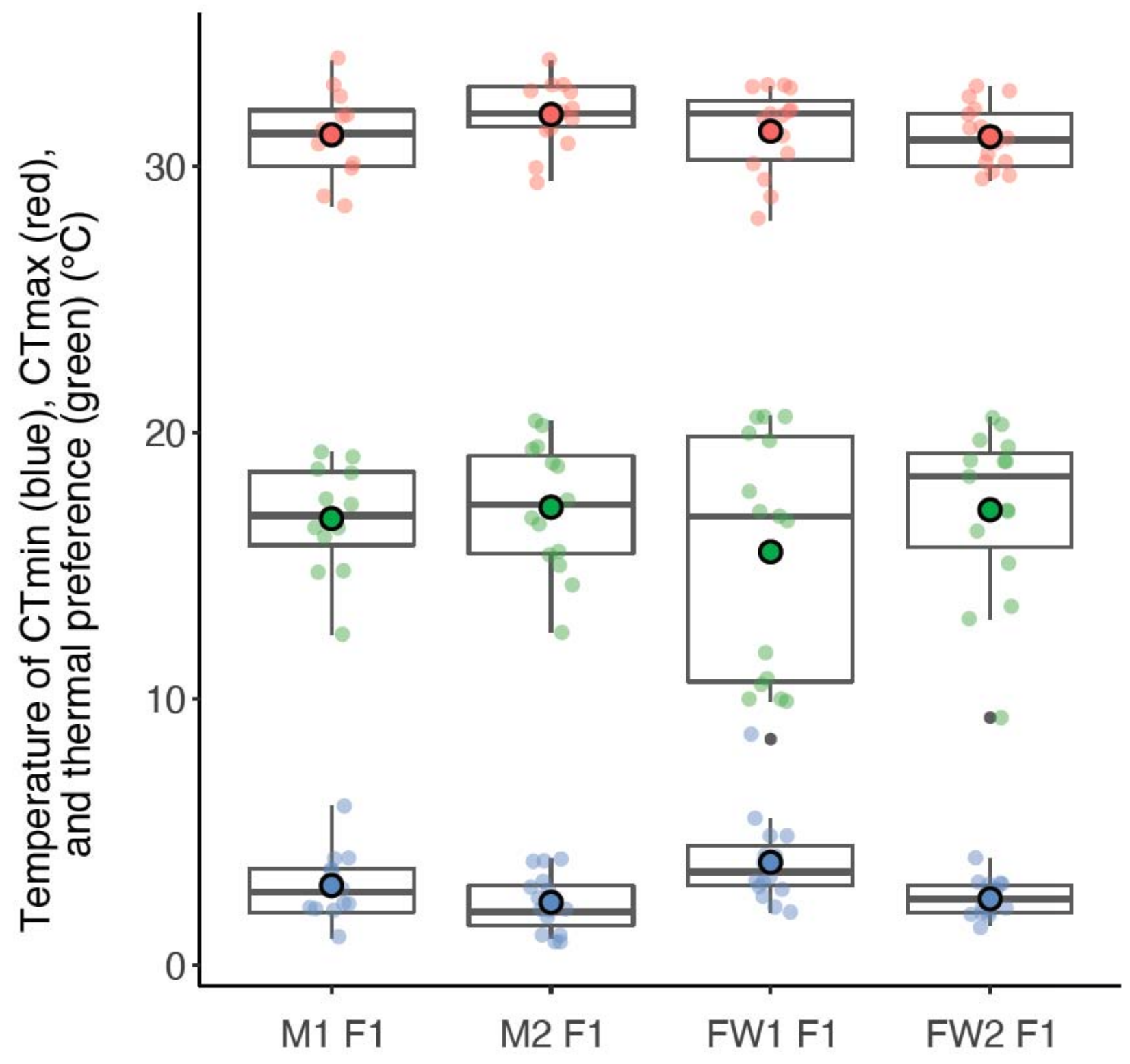

796 Figure S2. Thermal preference (green), critical thermal minimum (blue) and maximum (red) measurements for adult threespine stickleback (Gasterosteus aculeatus) from pure $798 \quad \mathrm{~F} 1$ marine $(\mathrm{M} * \mathrm{~F} 1)$ and freshwater $(\mathrm{FW} * \mathrm{~F} 1)$ families raised in a common garden under a 799 constant thermal environment. 


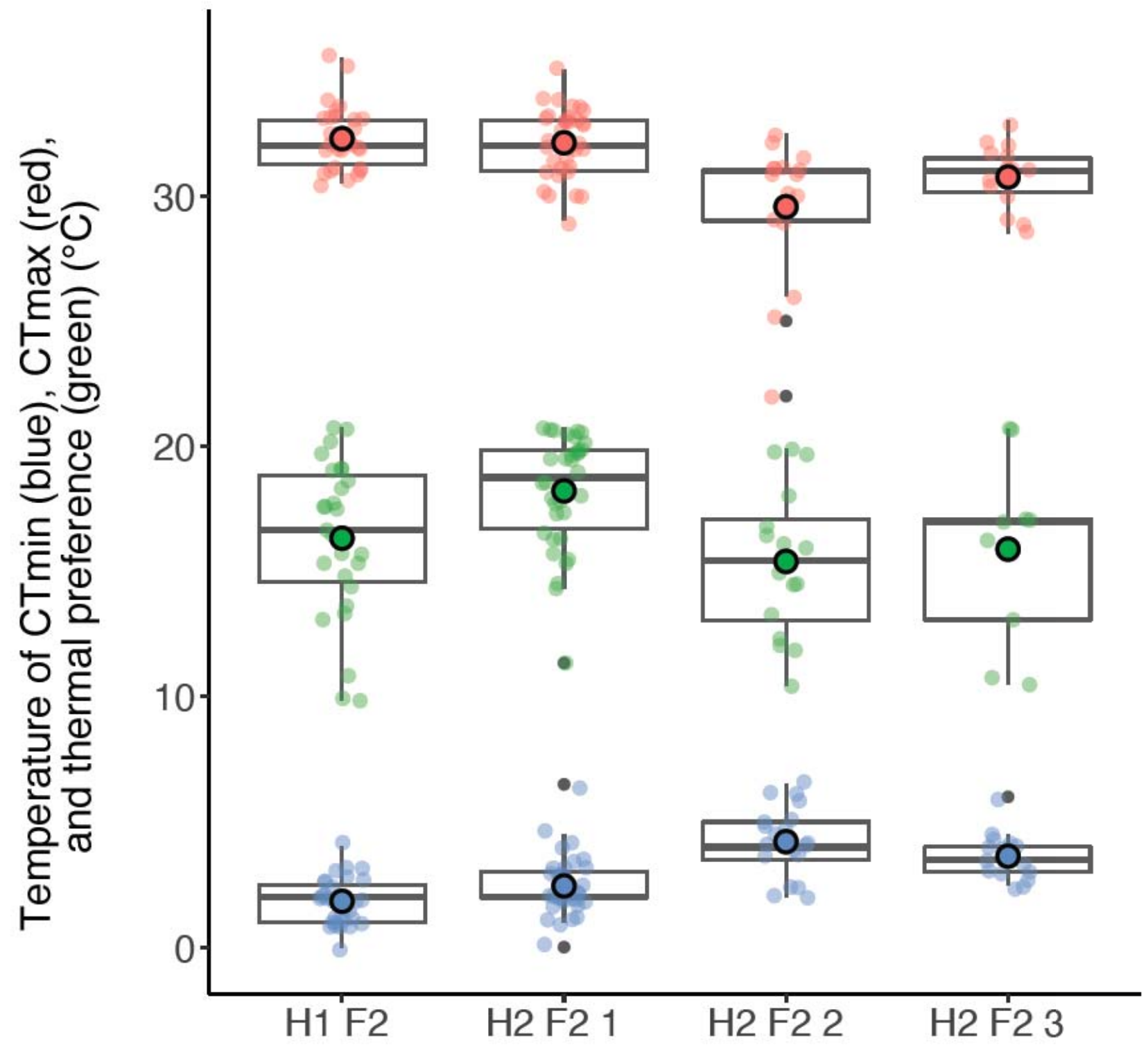

801 Figure S3. Thermal preference (green), critical thermal minimum (blue) and maximum 802 (red) measurements for adult threespine stickleback (Gasterosteus aculeatus) from hybrid 803 marine-freshwater F2 families raised in a common garden under a constant thermal 804 environment. 


\section{a) Linkage group III QTL}

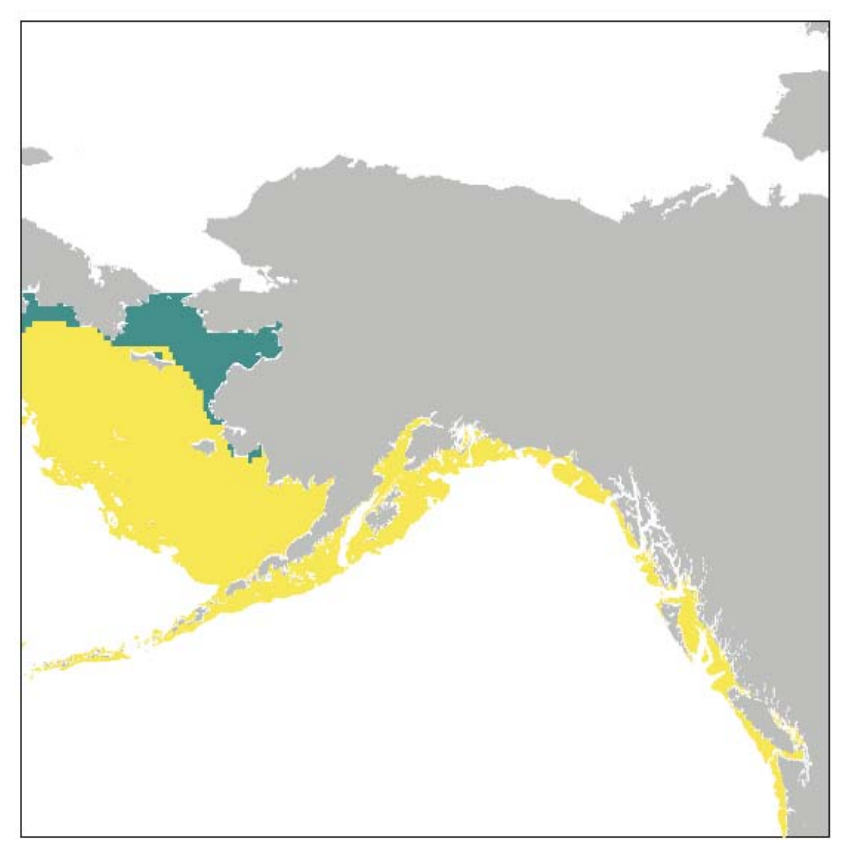

\section{b) Linkage group XXI QTL}

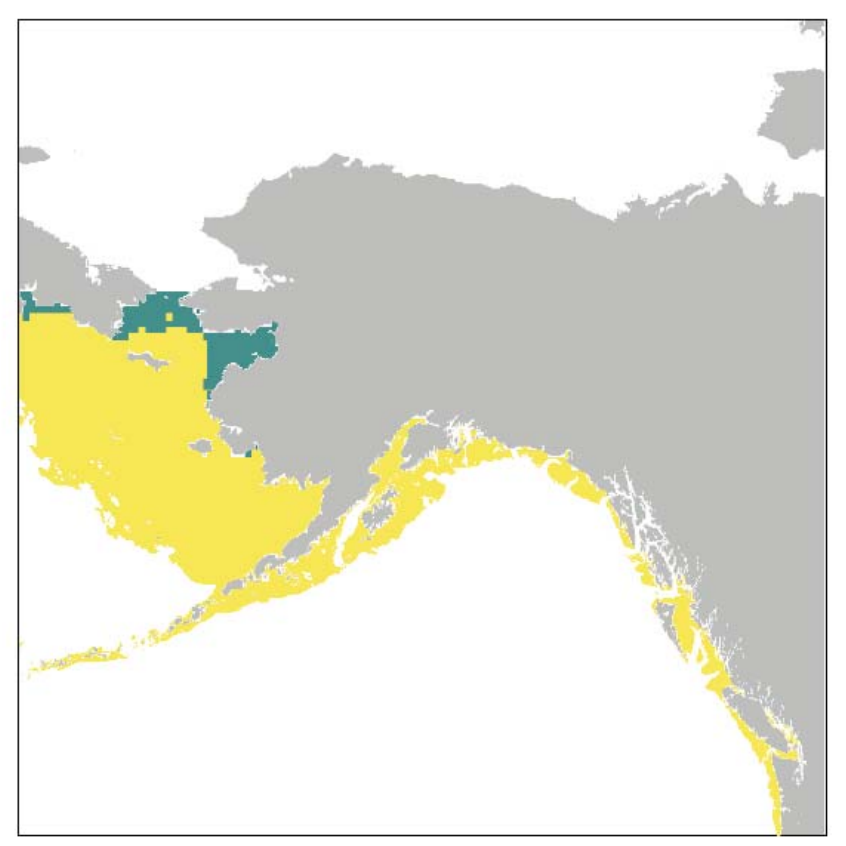

\section{$\square$ Within Physiological Limits}

Normal Behaviour

806 Figure S4. Changes in the distribution of marine threespine stickleback (Gasterosteus aculeatus) as a result of incorporating thermal

807 traits under IPCC end-of-century projections RCP 4.5 with trait evolution constrained by the underlying genetic architecture of critical

808 thermal minimum (CTmin) as determined from hybrid F2 mapping families in a) CTmin QTL on linkage group III and b) CTmin

809 QTL on linkage group XXI. 


\section{a) Linkage group III QTL}

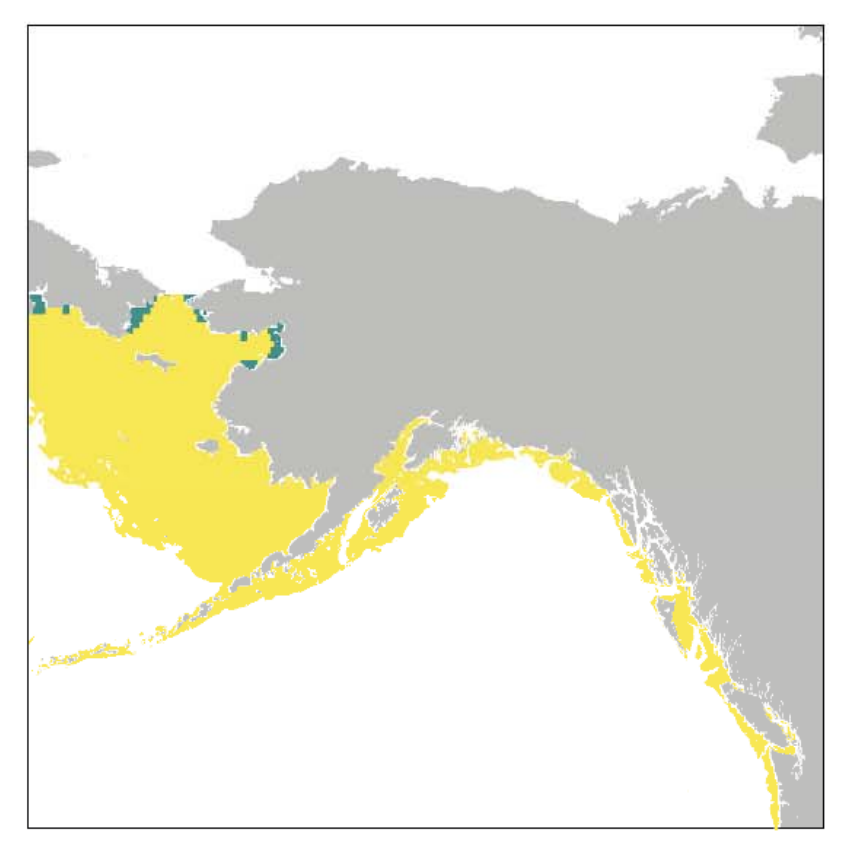

b) Linkage group XXI QTL

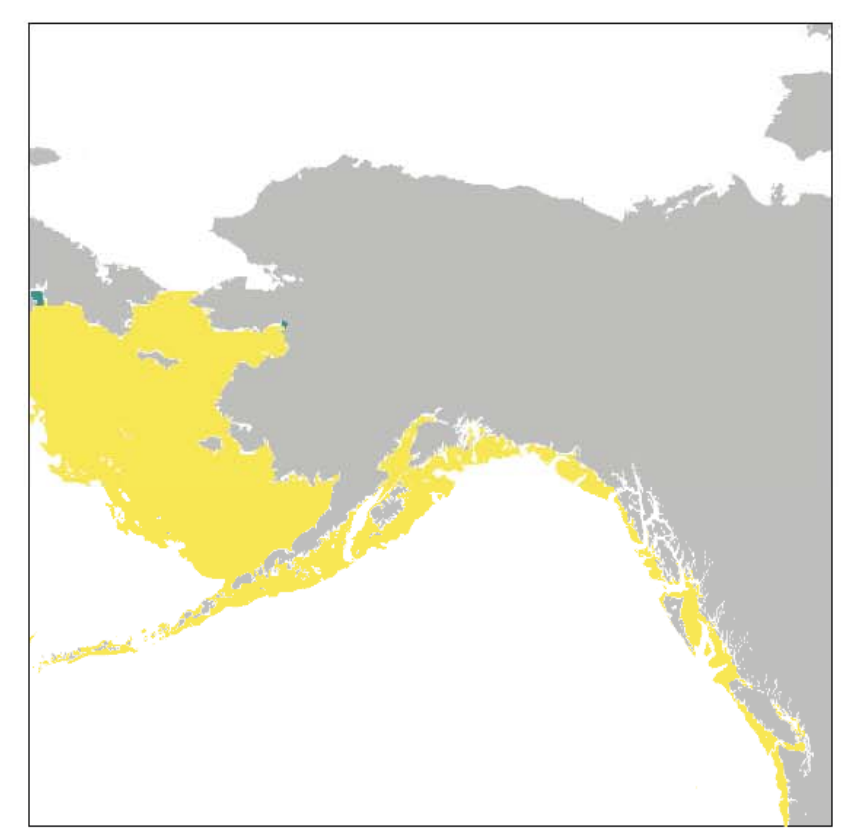

$\square$ Within Physiological Limits

$\square$ Normal Behaviour

811 Figure S5. Changes in the distribution of marine threespine stickleback (Gasterosteus aculeatus) as a result of incorporating thermal 812 traits under IPCC end-of-century projections RCP 8.5 with trait evolution constrained by the underlying genetic architecture critical 813 thermal maximum (CTmax) as determined from hybrid F2 mapping families in a) CTmin QTL on linkage group III and b) CTmin 814 QTL on linkage group XXI. 
815 Table S1. Summaries of linkage maps constructed for quantitative trait loci (QTL) analyses.

816

\begin{tabular}{|l|c|c|c|}
\hline Map & Nmarkers & Length (cM) & Average Maximum Spacing \\
\hline H1_F2 & 6571 & 1678.7 & 8.98 \\
\hline H2_F2 & 9930 & 1995.3 & 9.36 \\
\hline
\end{tabular}

817 
Table S2. Thermal trait data from Gasterosteus aculeatus used to inform the species distribution envelopes (rows) in the varied

\begin{tabular}{|c|c|c|c|c|c|}
\hline & Current day & No evolution & Evolution & $\begin{array}{l}\text { Adjusted PVE - } \\
\text { CTmin LG3 }\end{array}$ & $\begin{array}{l}\text { Adjusted PVE - } \\
\text { CTmin LG21 }\end{array}$ \\
\hline Normal Behaviour & $(5-25)$ & $(5-25)$ & $(2.5-25)$ & $(4.3-25)$ & $(3.66-25)$ \\
\hline $\begin{array}{l}\text { Within } \\
\text { Physiological } \\
\text { Limits }\end{array}$ & $(1.8-30.1)$ & $(1.8-30.1)$ & $(0-30.1)$ & $(1.07-30.1)$ & $(0.5-30.1)$ \\
\hline $\begin{array}{l}\text { Outside } \\
\text { Physiological } \\
\text { Limits }\end{array}$ & $30.1>x<1.8$ & $30.1>x<1.8$ & $30.1>x<0$ & $30.1>x<1.07$ & $30.1>x<0.5$ \\
\hline
\end{tabular}

